\title{
Circular RNAs in the tumour microenvironment
}

Zhonghua Ma ${ }^{1,2+} \mathbb{D}$, You Shuai ${ }^{3 \dagger}$, Xiangyu Gao ${ }^{1,2 \dagger}$, Xianzi Wen ${ }^{{ }^{*}}$ and Jiafu $\mathrm{Ji}^{1,2^{*}}$

\begin{abstract}
Background: Circular RNAs (circRNAs) are a new class of endogenous non-coding RNAs (ncRNAs) widely expressed in eukaryotic cells. Mounting evidence has highlighted circRNAs as critical regulators of various tumours. More importantly, circRNAs have been revealed to recruit and reprogram key components involved in the tumour microenvironment (TME), and mediate various signaling pathways, thus affecting tumourigenesis, angiogenesis, immune response, and metastatic progression.

Main body of the abstract: In this review, we briefly introduce the biogenesis, characteristics and classification of circRNAs, and describe various mechanistic models of circRNAs. Further, we provide the first systematic overview of the interplay between circRNAs and cellular/non-cellular counterparts of the TME and highlight the potential of circRNAs as prospective biomarkers or targets in cancer clinics. Finally, we discuss the biological mechanisms through which the circRNAs drive development of resistance, revealing the mystery of circRNAs in drug resistance of tumours.

Short conclusion: Deep understanding the emerging role of circRNAs and their involvements in the TME may provide potential biomarkers and therapeutic targets for cancer patients. The combined targeting of circRNAs and co-activated components in the TME may achieve higher therapeutic efficiency and become a new mode of tumour therapy in the future.
\end{abstract}

Keywords: Circular RNAs, Tumour microenvironment, Molecular mechanism, Biomarker, Target, Drug resistance

\section{Background}

Circular RNAs (circRNAs), a new class of endogenous non-coding RNAs (ncRNAs), were originally considered as non-functional by-products of aberrant splicing [1-3]. With the introduction of RNA-sequencing (RNA-seq) technology and bioinformatics, thousands of circRNAs are shown to be abundant in eukaryotic cells [2-5]. Moreover, the simultaneous use of prediction tools can benefit the unveiling of circRNAs, such as KNIFE, PTESFinder, MapSplice, CIRCexplorer and etc. [6]. Of note, miARma-Seq, a comprehensive pipeline analysis suite, is able to realize easy implementation of diverse algorithms [6]. Meanwhile, it is essential to perform accurate

\footnotetext{
* Correspondence: jijiafu@hsc.pku.edu.cn

'Zhonghua Ma, You Shuai and Xiangyu Gao contributed equally to this work.

'Key Laboratory of Carcinogenesis and Translational Research (Ministry of Education), Division of Gastrointestinal Cancer Translational Research Laboratory, Peking University Cancer Hospital \& Institute, Beijing, People's Republic of China

Full list of author information is available at the end of the article
}

quantification of circRNAs. Specifically, circRNAs expression can be validated by real-time quantitative polymerse chain reaction (RT-qPCR), micro-drop digital PCR, northern blot and in situ hybridization (ISH) [6].

Despite there is a fall of interest for some years, circRNAs have been identified as important hallmarks of various tumours [7-10]. Of note, tumour cells are not alone, since the tumour microenvironment (TME), as a key determinant in all stages of cancer development and progression, is a complex ecosystem involving the coevolution of both cancerous cells and the surrounding stroma [11]. Multiple cellular components in the TME include immune cells (T-cells, tumour associated macrophages (TAM), dendritic cells, mast cells etc.), cancerassociated endothelial cells (CAEs), cancer-associated fibroblasts (CAFs) and cancer stem cells (CSCs) $[12,13]$. Non-cellular counterparts consist of growth factors, cytokines, as well as extracellular matrix (ECM), which supplies not merely an inert place for this game $[12,13]$.

(C) The Author(s). 2020 Open Access This article is distributed under the terms of the Creative Commons Attribution 4.0 International License (http://creativecommons.org/licenses/by/4.0/), which permits unrestricted use, distribution, and 
Currently, the circRNA-based communication within the TME has greatly attracted the scientific community. The clinical prospects of cancer therapy, targeting key counterparts of the TME, are encouraging $[14,15]$. The establishment of circRNA-involved TME network may provide an opportunity for targeted therapy based on the interplay with circRNAs, facilitating the development of more effective therapeutics for various cancers [16, 17]. The most recent published reviews of circRNAs mainly focus on their biological roles in human cancers $[18,19]$. However, the current knowledge of interplay between circRNAs and TME has not been systematically summarized to date. In this review, we document the biogenesis, characteristics, and mechanistic models of circRNAs in various cancers. Moreover, we provide the first overview of the interplay between circRNAs and cellular/non-cellular counterparts of the TME and highlight the potential of circRNAs as prospective biomarkers or targets in cancer clinics. Finally, we discuss the biological mechanisms through which the circRNAs drive development of resistance, revealing the mystery of circRNAs in drug resistance of tumours.

\section{Biogenesis, classification and characteristics of circRNAs}

Early in 1976, circRNAs were firstly discovered in the Sendai virus and plant-infected viroids [5]. However, in the following decades, most circRNAs were considered as "splicing noise" or the by-products of RNA processing [3]. Despite various formations of circRNAs, most recently explored circRNAs are generated from precursor mRNAs (pre-mRNAs), where a downstream 5'splice donor site is linked to an upstream 3' splice acceptor site $[1,2]$.

With the advent and wide application of computational approaches and bioinformatics, the widespread expression of circRNAs has been uncovered in different cells among various species [20]. For example, Jeck et al. identified more than 25,000 circRNAs in cultured human fibroblasts [21]. Sebastian et al. detected approximately 2000 human, 1900 mouse and 700 nematode circRNAs from sequencing data [22]. Shortly after, Guo et al. developed a computational pipeline to expand identification of circRNAs from sequencing data [23]. Intriguingly, 7112 circRNAs was annotated from 39 biological samples with varied number of detectable circRNAs [23]. Based on the source of generation, circRNAs can be divided into four categories: exon circRNAs (ecircRNAs), intron circRNAs, exon-intron circRNAs (EIciRNAs), and intergenic circRNAs [24]. The biogenesis and classification of circRNAs are shown in Fig. 1 and Fig. 2. (1) More than 80\% of circRNAs are ecircRNAs that contain only $3^{\prime} \rightarrow 5^{\prime}$ linked exon sequences [25]. (2) Intron circRNA is a generic term for a class of circRNAs including circular intron RNAs (ciRNAs), excised group I introns, excised group II introns, excised tRNA introns and circRNAs that contain an internal lasso [26]. (3) EIciRNAs are nuclear circRNAs that are simultaneously circularized by exons and introns and contain $3^{\prime} \rightarrow 5^{\prime}$ linkage [3] (4) Intergenic circRNAs are another type of non-exon circRNAs found by circRNA identification(CIRI) [24]. However, the mechanism of circRNAs biogenesis still needs more research, revealing potential roles of circRNAs in the crucial processes.

It is known that circRNAs have remarkable characteristics, qualifying circRNAs as valuable biomarkers or targets in the clinics. (1) High stablity: circRNAs exhibit covalently closed loop structures, with absence of $5^{\prime}-3^{\prime}$ polarity and polyadenylated tails, and develop resistance to RNases, leading to higher stability compared with linear RNAs [21, 27]. (2) Prevalence and specificity: A large variety of circRNAs have been identified to display abundance in various species [28]. The enrichment of circRNAs can also found in saliva and blood [28]. Interestingly, circRNAs are expressed in tissue-specific and developmental stage-specific manners [8, 29]. (3) Conservation: Most circRNAs show high conservation in different species [30].

\section{Biological roles and mechanistic models of circRNAs}

Emerging studies have identified circRNAs as important regulators in various cancers [31-33]. For instance, For instance, Wang et al. revealed that circRHOT1 inhibited hepatocellular carcinoma (HCC) progression and functioned as a candidate biomarkers for HCC patients [34]. Yi et al. reported that circVimentin (VIM) participates in the regulation of lymphocyte adhesion and transcellular migration in acute myeloid leukemia (AML) [35]. Consistently, receiver operating characteristic (ROC) curve analysis suggested that circ-VIM is an unfavourable prognostic factor for AML patients [35]. Additionally, hsa_circ 0080145 amplification was identified in samples of chronic myeloid leukemia (CML) patients, and the regulatory axis of hsa_circ_0080145/miR-29b may potentially assist in diagnosis and treatments of CML [36]. Indeed, it is widely recognized that circRNAs show great promise as novel biomarkers or targets in multiple cancers [37-39]. Here we comprehensively summarized the dysregulated circRNAs in various tumours in Table 1. Mechanistically, circRNAs can act as miRNA sponges and transcriptional regulators, and interact with RNA-binding protein (RBP) [40-42]. Moreover, a handful of circRNAs can be translated into proteins/peptides [43]. The overview of the mechanistic models of circRNAs is shown in Fig. 3. 


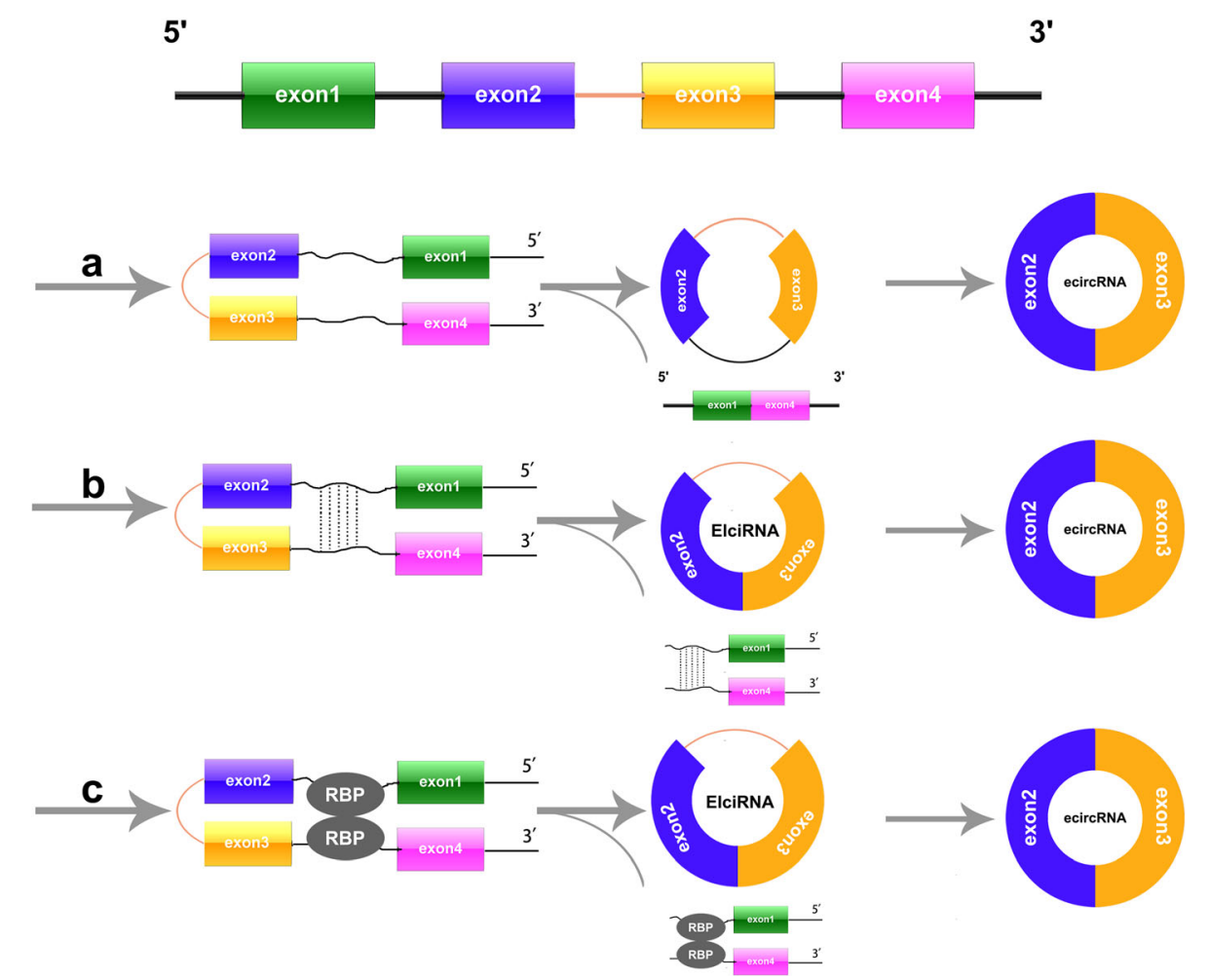

3'

Fig. 1 Biogenesis of ecircRNA and ElciRNA. a Exon skipping and formation of intra-lariat induced circulation. The splice donor in $3^{\prime}$ end of exon 1 and splice acceptor in $5^{\prime}$ end of exon 4 are covalently jointed together to form a RNA lariat containing skipped exons 2 and 3 . Then, an ecircRNA were further formed by removing introns. b. Intron-pairing-induced circularization. The flanking introns form a circRNA by base pairing. Then, ecircRNA or ElciRNA are produced through removing or retaining introns. c. RBP-pairing-induced circularization. RBPs interact with the sequence motifs of the upstream and downstream introns to build a bridge between introns, thus facilitating the head-to-tail end-joining of exon2 and exon3. In the end, a circular RNA is produced

\section{miRNA sponges}

MiRNAs, a class of abundant short ( 22 nucleotides) ncRNAs, modulate gene expression by directly base pairing to target sites in mRNAs [44]. In addition to mRNAs, pseudogenes and long non-coding RNAs (lncRNAs), many circRNAs have now been shown to regulate miRNA networks as competitive endogenous RNA (ceRNA) [32, 45, 46]. There are two characteristic circRNAs, namely circular RNA sponge for miR-7 (ciRS-7) and circRNA sex-determining region $\mathrm{Y}$ (cirSRY) $[47,48]$.

The first circRNA shown to serve as a miRNA sponge was ciRS-7, which contains more than 70 conservative binding sites for miRNA-7 [48]. Recently, it has been observed that ciRS-7 is highly expressed in multiple cancers, including colorectal cancer (CRC), GC, esophageal squamous cell carcinoma (ESCC) and non-small cell lung cancer (NSCLC) [47]. Amplification of ciRS-7 can block the tumour-suppressive activities of miR-7 and antagonize miR-7-meddiated phosphatase and tensin homolog (PTEN)/phosphatidylinositol 3-kinase (PI3K)/ AKT pathway, resulting in a more aggressive oncogenic phenotype in GC [49]. Additionally, Sang et al. revealed that ciRS-7 amplification drives ESCC progression partly through targeting miR-876-5p/MAGE-A family axis [50]. Another study concerning the role of ciRS-7 in ESCC demonstrated that ciRS-7 can prompt ESCC progression through miR-7/HOXB13/NF-kB or miR-7/ KLF4/NF- $\mathrm{kB}$ axis, providing novel prognostic indicators and therapeutic targets for ESCC patients [51, 52]. As for cir-SRY, a looped RNA specifically expressed in the mouse testis, it includes sixteen binding sites of miR138. The formation of cir-SRY/miR-138 axis was shown to be a general phenomenon [48].

Currently, a large number of circRNAs have been confirmed to serve as miRNA sponges, proposing a possible view that such a mechanism may be common to all circRNAs [53-55]. Shortly thereafter, following studies refuted the previously hypothesis, asserting that most circRNAs are not able to serve as miRNA sponges [23, 56, 57]. The main reason accounting for this assertion is that only a small portion of circRNAs possess multiple binding sites for specific miRNAs [23, 56, 57]. Gained from the most recently knowledge, we conclude that some circRNAs can behave as a sponge of specific miRNAs and induce the suppression of miRNAs. There are 


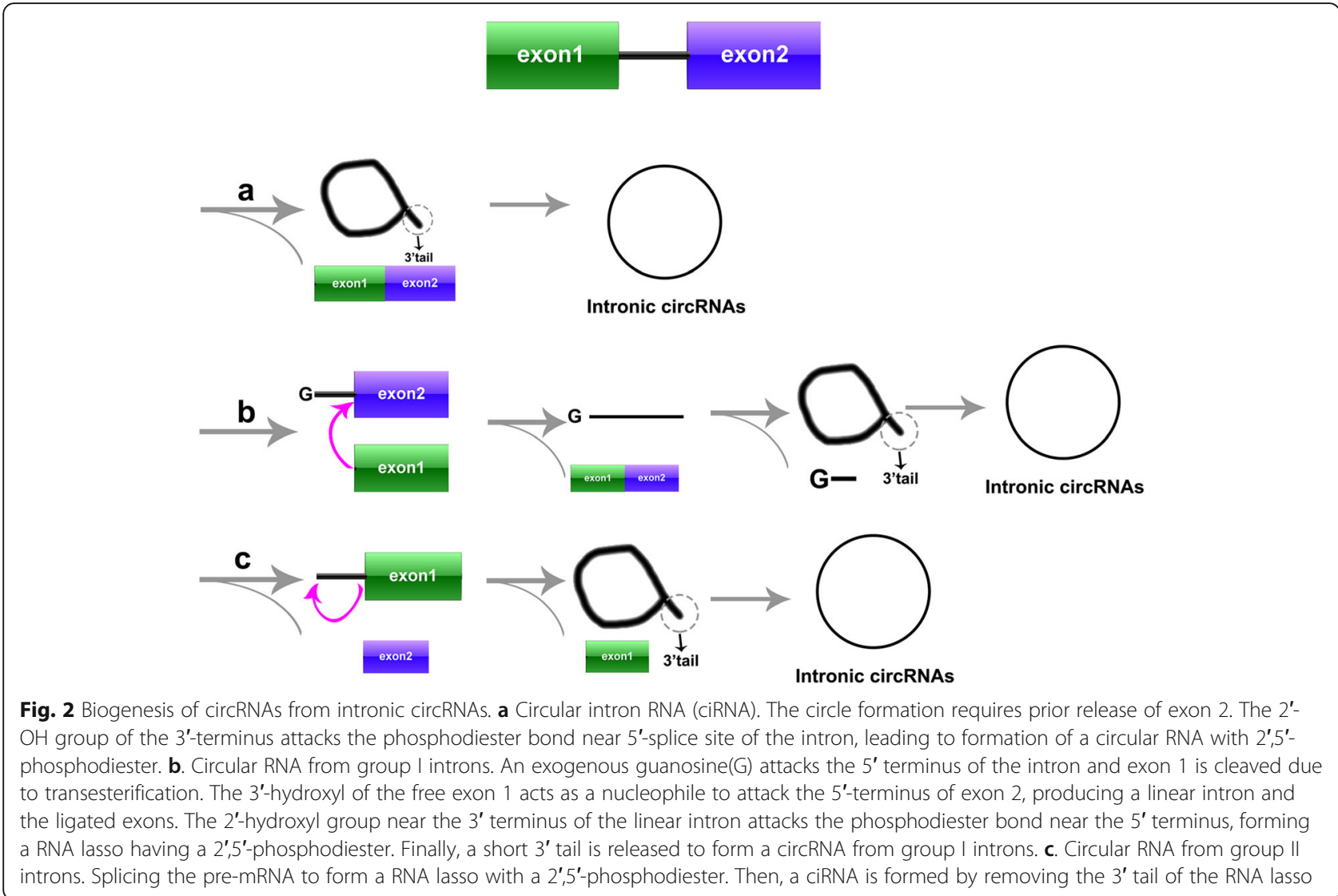

also other mechanisms for the regulation of circRNAs, since the mechanism of circRNAs as miRNA sponges is not existed in isolation.

\section{Interaction with RBPs}

In addition to miRNA "sponge" property, circRNAs can also bind to RNA-binding proteins (RBPs), competitively blocking protein-active elements in a sequence-specific manner $[16,58]$. Current investigations have illuminated that circRNA polyadenylatebinding nuclear protein 1 (circ-PABPN1) can bind to human antigen R (HUR) [41]. This extensive interaction displayed suppressive effects on the binding of HuR to PABPN1 mRNA, thus partially or completely blocking the translation of PABPN1 [41]. Another study showed that circRNA forkhead box $\mathrm{O} 3$ (circ-Foxo3) functioned as a scaffold and formed a circ-Foxo3-P21-cyclin dependent kinase 2 (CDK2) ternary complex, thus avoiding the formation of cyclin E/CDK2 complex [58]. This interacted complex can impact on cell proliferation and cell cycle regulation [58]. In addition, most recent studies also highlight that circ-Amotl1 can determine the subcellular translocation of several RBPs, such as pyruvate dehydrogenase kinase 1 (PDK1), MYC, and signal transducer and activator of transcription 3 (STAT3) [59-61].

\section{Regulators of transcription}

Many scholars have discovered that circRNAs can also regulate gene expression at transcriptional or posttranscriptional level [42, 62]. EIciRNAs and ciRNAs, which are primarily located in the nucleus, are likely to function at the transcriptional level [25, 26, 42]. For instance, EIciRNAs, such as circRNA eukaryotic translation initiation factor 3 subunit J (circ-EIF3J) and circRNA poly(A) binding protein interacting protein 2 (circ-PAIP2), are demonstrated to interact with RNA Pol II in combination with U1 snRNP to enhance the expression of their parental genes [42, 63]. Similarly, this mechanistic model can be found in ciRNAs and their parental gene. CiRNAs, such as ci-ankrd52 and ci-sirt7, interacted with Pol II and positively mediated the transcription of parental genes [26]. Of note, the regulation of transcription may be a common mechanism for circRNAs.

\section{Translation of circRNAs}

CircRNAs were initially recognized as ncRNAs without protein-coding abilities, due to the absence of a $5^{\prime}$ cap structure and poly(A) tail [43]. Interestingly, researchers uncovered the translation capacity of some circRNAs, which may carry open reading frame (ORF) [43]. Further studies found that circRNA zinc finger protein (circ- 
Table 1 The dysregulated circRNAs in various types of cancers

\begin{tabular}{|c|c|c|c|c|c|}
\hline Symbol & Function & Expression & Cancer Type & Mechanism & PMID \\
\hline $\begin{array}{l}\text { circ-ANAPC7 } \\
\text { (hsa_circ_0005785) }\end{array}$ & / & Upregulated & Acute Myeloid Leukemia. & circ-ANAPC7/miR-181 & $29,969,755$ \\
\hline hsa_circ_0075001 & / & Upregulated & Acute Myeloid Leukemia. & / & $28,971,903$ \\
\hline circ-DLEU2 & oncogene & Upregulated & Acute Myeloid Leukemia. & circ-DLEU2/miR-496/PRKACB & $30,037,980$ \\
\hline hsa_circ_0004277 & / & Downregulated & Acute Myeloid Leukemia. & / & $28,282,919$ \\
\hline circ-HIPK2 & / & Downregulated & Acute Myeloid Leukemia. & circ-HIPK2/miR-124-3p & $29,844,435$ \\
\hline hsa_circ_0075825 & / & Upregulated & Basal cell carcinoma & / & $27,097,056$ \\
\hline hsa_circ_0075828 & / & Upregulated & Basal cell carcinoma & / & $27,097,056$ \\
\hline hsa_circ_0022383 & / & Downregulated & Basal cell carcinoma & / & $27,298,156$ \\
\hline hsa_circ_0022392 & / & Downregulated & Basal cell carcinoma & / & $27,298,156$ \\
\hline $\begin{array}{l}\text { circRNA-MYLK } \\
\text { (hsa_circ_0002768) }\end{array}$ & oncogene & Upregulated & Bladder Cancer & circRNA-MYLK/miR-29a/NEGFANEGFR2 & $28,687,357$ \\
\hline $\begin{array}{l}\text { circTCF25 } \\
\text { (hsa_circ_0041103) }\end{array}$ & oncogene & Upregulated & Bladder Cancer & circTCF25/miR-103-3p/miR-107/CDK6 & $27,484,176$ \\
\hline circ-BCRC4 & $\begin{array}{l}\text { tumor } \\
\text { suppressor }\end{array}$ & Downregulated & Bladder Cancer & circ-BCRC4.miR-101/EZH2 & $29,270,748$ \\
\hline circ-ITCH & $\begin{array}{l}\text { tumor } \\
\text { suppressor }\end{array}$ & Downregulated & Bladder Cancer & circ-ITCH/miR-17/miR-224/p21/PTEN & $29,386,015$ \\
\hline circHIPK3 & $\begin{array}{l}\text { tumor } \\
\text { suppressor }\end{array}$ & Downregulated & Bladder Cancer & circHIPK3/miR-558/HPSE & $28,794,202$ \\
\hline $\begin{array}{l}\text { circ-ABCB10 } \\
\text { (hsa_circ_0008717) }\end{array}$ & oncogene & Upregulated & Breast Cancer & circ-ABCB10/miR-1271 & $28,744,405$ \\
\hline circ-DENND4C & oncogene & Upregulated & Breast Cancer & HIF1a/circ-DENND4C & $28,739,726$ \\
\hline $\begin{array}{l}\text { circGFRA1 } \\
\text { (hsa_circ_0005239) }\end{array}$ & oncogene & Upregulated & Breast Cancer & circGFRA1/miR-34a/GFRA1 & $29,037,220$ \\
\hline hsa_circ_0001982 & oncogene & Upregulated & Breast Cancer & hsa_circ_0001982/miR-143 & $28,933,584$ \\
\hline hsa_circ_0011946 & oncogene & Upregulated & Breast Cancer & hsa_circ_0011946/miR-26a/miR-26b / RFC3 & $29,593,432$ \\
\hline circ-Foxo3 & $\begin{array}{l}\text { tumor } \\
\text { suppressor }\end{array}$ & Downregulated & Breast Cancer & $\begin{array}{l}\mathrm{p} 53 / \mathrm{miR}-22 / \mathrm{miR}-136 / \mathrm{miR}-138 / \mathrm{miR}-149 / \\
\mathrm{miR}-433 / \mathrm{miR}-762 / \mathrm{miR}-3614-5 \mathrm{p} / \mathrm{miR}-3622 \mathrm{~b}-5 \mathrm{p}\end{array}$ & $\begin{array}{l}27,886,165 / \\
26657152\end{array}$ \\
\hline hsa_circ_000911 & $\begin{array}{l}\text { tumor } \\
\text { suppressor }\end{array}$ & Downregulated & Breast Cancer & hsa_circ_000911/miR-449a/Notch1 & $29,431,182$ \\
\hline hsa_circ_0000284 & oncogene & Upregulated & Cervical Cancer & hsa_circ_0000284/miR-506/Snail-2 & $29,511,454$ \\
\hline hsa_circ_0023404 & oncogene & Upregulated & Cervical Cancer & hsa_circ_0023404/miR-5047/NEGFA & $31,082,770$ \\
\hline $\begin{array}{l}\text { CDR1as (hsa_circ_ } \\
0001946, \text { ciRS-7) }\end{array}$ & oncogene & Upregulated & Cholangiocarcinoma & / & $29,424,892$ \\
\hline hsa_circ_0001649 & $\begin{array}{l}\text { tumor } \\
\text { suppressor }\end{array}$ & Downregulated & Cholangiocarcinoma & / & $29,337,065$ \\
\hline circ-CBFB & oncogene & Upregulated & $\begin{array}{l}\text { Chronic Lymphocytic } \\
\text { Leukemia }\end{array}$ & circ-CBFB/miR-607/FZD3/Wnt/ $\beta$-catenin & $29,902,450$ \\
\hline circ_0132266 & / & Downregulated & $\begin{array}{l}\text { Chronic Lymphocytic } \\
\text { Leukemia }\end{array}$ & circ_0132266/miR-337-3p/PML & $31,152,142$ \\
\hline circ-BA9.3 & oncogene & Upregulated & $\begin{array}{l}\text { Chronic Myelogenous } \\
\text { Leukaemia }\end{array}$ & circ-BA9.3/ABL1/BCR-ABL1 & $30,224,298$ \\
\hline hsa_circ_0080145 & oncogene & Upregulated & $\begin{array}{l}\text { Chronic Myelogenous } \\
\text { Leukaemia }\end{array}$ & hsa_circ_0080145/miR-29b & $30,205,959$ \\
\hline hsa_circ_0001793 & / & Upregulated & Colorectal Cancer & / & $25,624,062$ \\
\hline circ_001569 & oncogene & Upregulated & Colorectal Cancer & circ_001569/miR-145/E2F5/BAG4/FMNL2 & $27,058,418$ \\
\hline circ-BANP & oncogene & Upregulated & Colorectal Cancer & circ-BANP/p-Akt & $28,103,507$ \\
\hline circCCDC66 & oncogene & Upregulated & Colorectal Cancer & $\operatorname{circCCDC66/miR-33b/miR-93~}$ & $28,249,903$ \\
\hline circHIPK3 & oncogene & Upregulated & Colorectal Cancer & circ-HIPK/miR-7/FAK/IGF1R/ EGFR/YY1 & $29,549,306$ \\
\hline
\end{tabular}


Table 1 The dysregulated circRNAs in various types of cancers (Continued)

\begin{tabular}{|c|c|c|c|c|c|}
\hline$\overline{\text { Symbol }}$ & Function & Expression & Cancer Type & Mechanism & PMID \\
\hline hsa_circ_0000069 & oncogene & Upregulated & Colorectal Cancer & / & $28,003,761$ \\
\hline $\begin{array}{l}\text { CDR1as (hsa_circ_ } \\
\text { 0001946, ciRS-7) }\end{array}$ & oncogene & Upregulated & Colorectal Cancer & hsa_circ_0001946/miR-7/EGFR/ RAF1 & $\begin{array}{l}25,624,062 / \\
28174233\end{array}$ \\
\hline hsa_circ_0007534 & oncogene & Upregulated & Colorectal Cancer & / & $29,364,478$ \\
\hline hsa_circ_000984 & oncogene & Upregulated & Colorectal Cancer & hsa_circ_000984/miR-106b/CDK6 & $29,207,676$ \\
\hline hsa_circ_0020397 & oncogene & Upregulated & Colorectal Cancer & hsa_circ_0020397/miR-138/TERT/ PD-L1 & $28,707,774$ \\
\hline hsa_circ_0136666 & oncogene & Upregulated & Colorectal Cancer & hsa_circ_0136666/miR-136/SH2B1 & $30,370,521$ \\
\hline hsa_circ_0000523 & / & Downregulated & Colorectal Cancer & / & $25,624,062$ \\
\hline hsa_circ_0001346 & / & Downregulated & Colorectal Cancer & / & $25,624,062$ \\
\hline hsa_circ_0001649 & / & Downregulated & Colorectal Cancer & / & $29,421,663$ \\
\hline Cir-ITCH & $\begin{array}{l}\text { tumor } \\
\text { suppressor }\end{array}$ & Downregulated & Colorectal Cancer & $\begin{array}{l}\text { cir-ITCH/miR-7/ miR-20a/ miR-214/Wnt/ } \\
\beta \text {-catenin }\end{array}$ & $26,110,611$ \\
\hline hsa_circ_0003906 & $\begin{array}{l}\text { tumor } \\
\text { suppressor }\end{array}$ & Downregulated & Colorectal Cancer & / & $29,123,417$ \\
\hline $\begin{array}{l}\text { cric-FBXW7 (hsa_ } \\
\text { circ_001988) }\end{array}$ & $\begin{array}{l}\text { tumor } \\
\text { suppressor }\end{array}$ & Downregulated & Colorectal Cancer & / & $26,884,878$ \\
\hline hsa_circ_0070933 & / & Upregulated & $\begin{array}{l}\text { Cutaneous squamous cell } \\
\text { carcinoma }\end{array}$ & / & $27,298,156$ \\
\hline hsa_circ_0070934 & / & Upregulated & $\begin{array}{l}\text { Cutaneous squamous cell } \\
\text { carcinoma }\end{array}$ & / & $27,298,156$ \\
\hline hsa_circ_0022383 & / & Downregulated & $\begin{array}{l}\text { Cutaneous squamous cell } \\
\text { carcinoma }\end{array}$ & / & $27,298,156$ \\
\hline hsa_circ_0022392 & / & Downregulated & $\begin{array}{l}\text { Cutaneous squamous cell } \\
\text { carcinoma }\end{array}$ & / & $27,298,156$ \\
\hline circ-HIPK3 & oncogene & Upregulated & Epithelial Ovarian Cancer & / & $29,949,144$ \\
\hline circ-SLC7A5 & oncogene & Upregulated & $\begin{array}{l}\text { Esophageal squamous cell } \\
\text { carcinoma }\end{array}$ & / & $31,726,270$ \\
\hline $\begin{array}{l}\text { circPRKCl (hsa_circ_ } \\
\text { 0067934) }\end{array}$ & oncogene & Upregulated & $\begin{array}{l}\text { Esophageal squamous cell } \\
\text { carcinoma }\end{array}$ & / & $27,752,108$ \\
\hline hsa_circ_0000518 & / & Downregulated & $\begin{array}{l}\text { Esophageal squamous cell } \\
\text { carcinoma }\end{array}$ & $\begin{array}{l}\text { hsa_circ_0000518/miR-181a-2/ miR-512-5p/ } \\
\text { miR-521/ miR-556-5p/ miR-663b/ miR-1204 }\end{array}$ & $27,465,405$ \\
\hline hsa_circ_0000554 & / & Downregulated & $\begin{array}{l}\text { Esophageal squamous cell } \\
\text { carcinoma }\end{array}$ & $\begin{array}{l}\text { hsa_circ_0000554/miR-30c-1/ miR-30c-2/ } \\
\text { miR-122/ miR-139-3p/ miR-339-5p/ miR-1912 }\end{array}$ & $27,465,405$ \\
\hline circ-ITCH & $\begin{array}{l}\text { tumor } \\
\text { suppressor }\end{array}$ & Downregulated & $\begin{array}{l}\text { Esophageal squamous cell } \\
\text { carcinoma }\end{array}$ & miR-7/ miR-17/ miR-214/Wnt/ß-catenin & $25,749,389$ \\
\hline $\begin{array}{l}\text { circPVT1 (hsa_circ_ } \\
0001821 \text { ) }\end{array}$ & / & Upregulated & Gastric Cancer & / & $31,616,472$ \\
\hline circLMTK2 & oncogene & Upregulated & Gastric Cancer & circLMTK2/miR-150-5p/c-Myc & $31,722,712$ \\
\hline has-circRNA7690-15 & oncogene & Upregulated & Gastric Cancer & / & $28,980,874$ \\
\hline hsa_circ_0047905 & oncogene & Upregulated & Gastric Cancer & / & $28,980,874$ \\
\hline hsa_circ_0138960 & oncogene & Upregulated & Gastric Cancer & / & $28,980,874$ \\
\hline hsa_circ_0001017 & / & Downregulated & Gastric Cancer & / & $29,098,316$ \\
\hline hsa_circ_0001649 & / & Downregulated & Gastric Cancer & / & $28,167,847$ \\
\hline hsa_circ_0003159 & / & Downregulated & Gastric Cancer & / & $28,618,205$ \\
\hline hsa_circ_0014717 & / & Downregulated & Gastric Cancer & / & $28,544,609$ \\
\hline hsa_circ_0061276 & / & Downregulated & Gastric Cancer & / & $29,098,316$ \\
\hline hsa_circ_0074362 & / & Downregulated & Gastric Cancer & / & $29,240,459$ \\
\hline hsa_circ_002059 & $\begin{array}{l}\text { tumor } \\
\text { suppressor }\end{array}$ & Downregulated & Gastric Cancer & / & $25,689,795$ \\
\hline
\end{tabular}


Table 1 The dysregulated circRNAs in various types of cancers (Continued)

\begin{tabular}{|c|c|c|c|c|c|}
\hline$\overline{\text { Symbol }}$ & Function & Expression & Cancer Type & Mechanism & PMID \\
\hline $\begin{array}{l}\text { circ-LPHN2 (hsa_ } \\
\text { circRNA_100269) }\end{array}$ & $\begin{array}{l}\text { tumor } \\
\text { suppressor }\end{array}$ & Downregulated & Gastric Cancer & hsa_circRNA_100269/miR-630 & $28,657,541$ \\
\hline $\begin{array}{l}\text { circ-HuR (hsa_circ_ } \\
\text { 0049027) }\end{array}$ & $\begin{array}{l}\text { tumor } \\
\text { suppressor }\end{array}$ & Downregulated & Gastric Cancer & circ-HuR/CNBP & $31,718,709$ \\
\hline circLARP4 & $\begin{array}{l}\text { tumor } \\
\text { suppressor }\end{array}$ & Downregulated & Gastric Cancer & circLARP4/miR-424/LATS1 & $28,893,265$ \\
\hline hsa_circ_0000096 & $\begin{array}{l}\text { tumor } \\
\text { suppressor }\end{array}$ & Downregulated & Gastric Cancer & $\begin{array}{l}\text { hsa_circ_0000096/cyclin D1/CDK6/ MMP2/ } \\
\text { MMP9 }\end{array}$ & $28,081,541$ \\
\hline hsa_circ_0000181 & $\begin{array}{l}\text { tumor } \\
\text { suppressor }\end{array}$ & Downregulated & Gastric Cancer & / & $28,940,688$ \\
\hline hsa_circ_0000190 & $\begin{array}{l}\text { tumor } \\
\text { suppressor }\end{array}$ & Downregulated & Gastric Cancer & / & $28,130,019$ \\
\hline hsa_circ_0000520 & $\begin{array}{l}\text { tumor } \\
\text { suppressor }\end{array}$ & Downregulated & Gastric Cancer & / & $29,103,021$ \\
\hline hsa_circ_0000745 & $\begin{array}{l}\text { tumor } \\
\text { suppressor }\end{array}$ & Downregulated & Gastric Cancer & / & $28,974,900$ \\
\hline hsa_circ_0001895 & $\begin{array}{l}\text { tumor } \\
\text { suppressor }\end{array}$ & Downregulated & Gastric Cancer & / & $28,443,463$ \\
\hline hsa_circ_0067582 & $\begin{array}{l}\text { tumor } \\
\text { suppressor }\end{array}$ & Downregulated & Gastric Cancer & / & $31,721,300$ \\
\hline circ-VCAN & / & Upregulated & Gliomas & / & $26,873,924$ \\
\hline circ_0001730 & oncogene & Upregulated & Gliomas & circ_0001730/miR-326/Wnt7B & $31,304,776$ \\
\hline circ-SHKBP1 & oncogene & Upregulated & Gliomas & circ-SHKBP1/miR-544a/miR-379/FOXP1/FOXP2 & $29,499,945$ \\
\hline circ-ZNF292 & oncogene & Upregulated & Gliomas & circ-ZNF292/Wnt/B-catenin & $27,613,831$ \\
\hline $\begin{array}{l}\text { circTTBK2 (hsa_circ_ } \\
0000594)\end{array}$ & oncogene & Upregulated & Gliomas & circTTBK2/miR-217/HNF1ß/Derlin-1 & $28,219,405$ \\
\hline $\begin{array}{l}\text { cric-FBXW7 (hsa_circ_ } \\
\text { 001988) }\end{array}$ & oncogene & Upregulated & Gliomas & / & $28,903,484$ \\
\hline hsa_circ_0046701 & oncogene & Upregulated & Gliomas & hsa_circ_0046701/miR-142/ITGB8 & $29,337,055$ \\
\hline $\begin{array}{l}\text { CDR1as (hsa_circ } \\
0001946, \text {,iRS-7) }\end{array}$ & / & Downregulated & Gliomas & miR-671-5p/CDR1as/CDR1/NSNL1 & $26,683,098$ \\
\hline circ-BRAF & / & Downregulated & Gliomas & / & $28,236,760$ \\
\hline circ-SHPRH & $\begin{array}{l}\text { tumor } \\
\text { suppressor }\end{array}$ & Downregulated & Gliomas & / & $29,343,848$ \\
\hline $\begin{array}{l}\text { circSMARCA5(hsa } \\
\text { circ_0001445) }\end{array}$ & $\begin{array}{l}\text { tumor } \\
\text { suppressor }\end{array}$ & Downregulated & Gliomas & circSMARCA5/SRSF1 & $29,415,469$ \\
\hline circRNA_100338 & / & Upregulated & Hepatocellular Carcinoma & circRNA_100338/miR-141-3p & $\begin{array}{l}31,157,168 / \\
28710406\end{array}$ \\
\hline hsa_circ_0000284 & / & Upregulated & Hepatocellular Carcinoma & $\begin{array}{l}\text { hsa_circ_0000284/miR-124/miR-152/miR-193a/ } \\
\text { miR-29a/miR-29b/miR-338/miR-379/miR-584/ } \\
\text { miR-654 }\end{array}$ & $27,050,392$ \\
\hline circ_000839 & oncogene & Upregulated & Hepatocellular Carcinoma & circ_000839/miR-200b & $28,695,771$ \\
\hline $\begin{array}{l}\text { circPRKCl (hsa_ } \\
\text { circ_0067934) }\end{array}$ & oncogene & Upregulated & Hepatocellular Carcinoma & $\begin{array}{l}\text { has_circ_0067934/miR-1324/FZD5/Wnt/ } \\
\text { ß-catenin }\end{array}$ & $29,458,020$ \\
\hline hsa_circ_0005075 & oncogene & Upregulated & Hepatocellular Carcinoma & / & $27,258,521$ \\
\hline $\begin{array}{l}\text { CDR1as (hsa_circ } \\
\text { 0001946, ciRS-7) }\end{array}$ & / & Downregulated & Hepatocellular Carcinoma & hsa_circ_0001946/miR-7/EGFR/CCNE1/PIK3CD & $\begin{array}{l}28,892,615 / \\
27391479\end{array}$ \\
\hline hsa_circ_0001649 & / & Downregulated & Hepatocellular Carcinoma & / & $26,600,397$ \\
\hline hsa_circ_0004018 & / & Downregulated & Hepatocellular Carcinoma & / & $28,938,566$ \\
\hline hsa_circ_0067531 & / & Downregulated & Hepatocellular Carcinoma & / & $29,251,325$ \\
\hline circC3P1 & tumor & Downregulated & Hepatocellular Carcinoma & circC3P1/miR-4641/PCK1 & $29,608,893$ \\
\hline
\end{tabular}


Table 1 The dysregulated circRNAs in various types of cancers (Continued)

\begin{tabular}{|c|c|c|c|c|c|}
\hline Symbol & Function & Expression & Cancer Type & Mechanism & PMID \\
\hline $\begin{array}{l}\text { circMTO1 (hsa_circ_ } \\
\text { 0007874) }\end{array}$ & $\begin{array}{l}\text { tumor } \\
\text { suppressor }\end{array}$ & Downregulated & Hepatocellular Carcinoma & circMTO1/miR-9/p21 & $28,520,103$ \\
\hline $\begin{array}{l}\text { circSMARCA5 (hsa_ } \\
\text { circ_0001445) }\end{array}$ & $\begin{array}{l}\text { tumor } \\
\text { suppressor }\end{array}$ & Downregulated & Hepatocellular Carcinoma & circSMARCA5 /miR-17-3p/miR-181-5p/TIMP3 & $29,378,234$ \\
\hline $\begin{array}{l}\text { circZKSCAN1 (hsa } \\
\text { circ_0001727) }\end{array}$ & $\begin{array}{l}\text { tumor } \\
\text { suppressor }\end{array}$ & Downregulated & Hepatocellular Carcinoma & / & $28,211,215$ \\
\hline hsa_circ_0003570 & $\begin{array}{l}\text { tumor } \\
\text { suppressor }\end{array}$ & Downregulated & Hepatocellular Carcinoma & / & $28,493,512$ \\
\hline hsa_circ_0005986 & $\begin{array}{l}\text { tumor } \\
\text { suppressor }\end{array}$ & Downregulated & Hepatocellular Carcinoma & hsa_circ_0005986/miR-129/Notch1 & $28,410,211$ \\
\hline circRNA_100876 & / & Upregulated & Lung Cancer & / & $28,343,871$ \\
\hline circ-CER & oncogene & Upregulated & Lung Cancer & circ-CER/miR-136/MMP13 & $28,343,871$ \\
\hline circMAN2B2 & oncogene & Upregulated & Lung Cancer & circMAN2B2/miR-1275/FOXK1 & $29,550,475$ \\
\hline $\begin{array}{l}\text { circPRKCl (hsa_- } \\
\text { circ_0067934) }\end{array}$ & oncogene & Upregulated & Lung Cancer & circPRKCl/miR-545/ miR-589/E2F7 & $29,588,350$ \\
\hline circRNA_102231 & oncogene & Upregulated & Lung Cancer & / & $29,602,132$ \\
\hline hsa_circ_0000064 & oncogene & Upregulated & Lung Cancer & hsa_circ_0000064/MMP2/MMP9 & $29,223,555$ \\
\hline hsa_circ_0007385 & oncogene & Upregulated & Lung Cancer & hsa_circ_0007385/miR-181 & $29,372,377$ \\
\hline hsa_circ_0012673 & oncogene & Upregulated & Lung Cancer & hsa_circ_0012673/miR-22/ErbB3 & $29,366,790$ \\
\hline hsa_circ_0013958 & oncogene & Upregulated & Lung Cancer & hsa_circ_0013958/miR-134/cyclin D1 & $28,685,964$ \\
\hline hsa_circ_0014130 & oncogene & Upregulated & Lung Cancer & / & $29,440,731$ \\
\hline circRNA-FOXO3 & $\begin{array}{l}\text { tumor } \\
\text { suppressor }\end{array}$ & Downregulated & Lung Cancer & / & $29,620,202$ \\
\hline hsa_circ_0013958 & $\begin{array}{l}\text { tumor } \\
\text { suppressor }\end{array}$ & Downregulated & Lung Cancer & $\begin{array}{l}\text { hsa_circ_0013958/miR-7/miR-214/Wnt/ } \\
\text { b-catenin }\end{array}$ & $27,642,589$ \\
\hline circDOCK1 & oncogene & Upregulated & $\begin{array}{l}\text { Oral Squamous Cell } \\
\text { Carcinoma }\end{array}$ & circDOCK1/mi-196a/BIRC3 & $29,286,141$ \\
\hline hsa_circRNA_103801 & / & Upregulated & Osteosarcoma & hsa_circRNA_103801/miR-370 & $28,957,794$ \\
\hline circ_0102049 & oncogene & Upregulated & Osteosarcoma & circ_0102049/miR-1304-5p/MDM2 & $31,727,503$ \\
\hline circ-UBAP2 & oncogene & Upregulated & Osteosarcoma & circ-UBAP2 /miR-143 & $28,977,896$ \\
\hline $\begin{array}{l}\text { circPVT1 (hsa_- } \\
\text { circ_0001821) }\end{array}$ & oncogene & Upregulated & Osteosarcoma & circPVT1/ABCB1 & $29,559,849$ \\
\hline hsa_circ_0001564 & oncogene & Upregulated & Osteosarcoma & hsa_circ_0001564/miR-29c & $29,229,385$ \\
\hline hsa_circ_0009910 & oncogene & Upregulated & Osteosarcoma & circ-UBAP2/miR-449a/IL-6R/JAK1/STAT3 & $29,117,539$ \\
\hline hsa_circ_0016347 & oncogene & Upregulated & Osteosarcoma & hsa_circ_0016347/miR-124/caspase-1 & $28,424,426$ \\
\hline hsa_circRNA_104980 & / & Downregulated & Osteosarcoma & / & $28,957,794$ \\
\hline hsa_circ_0005397 & / & Upregulated & Pancreatic cancer & $\begin{array}{l}\text { hsa_circ_0005397/miR-26b/miR-125a/miR-181a/ } \\
\text { miR-330/miR-382 }\end{array}$ & $27,997,903$ \\
\hline circ-ASH2L & oncogene & Upregulated & Pancreatic cancer & circ-ASH2L/miR-34a/Notch1 & $31,718,694$ \\
\hline circ-LDLRAD3 & oncogene & Upregulated & Pancreatic cancer & / & $29,307,994$ \\
\hline circRNA_100782 & oncogene & Upregulated & Pancreatic cancer & circRNA_100782/miR-124/IL6/STAT & $29,255,366$ \\
\hline $\begin{array}{l}\text { circ-ANAPC7 (hsa_ } \\
\text { circ_0005785) }\end{array}$ & / & Downregulated & Pancreatic cancer & $\begin{array}{l}\text { hsa_circ_0005785/miR-181a/miR-181b/ } \\
\text { miR-181d/miR-338/miR-526b }\end{array}$ & $27,997,903$ \\
\hline circ-SMARCA5 & oncogene & Upregulated & Prostate cancer & / & $28,765,045$ \\
\hline $\begin{array}{l}\text { circMTO1 (hsa_ } \\
\text { circ_0007874) }\end{array}$ & $\begin{array}{l}\text { tumor } \\
\text { suppressor }\end{array}$ & Downregulated & Prostate cancer & circMTO1/miR-17-5p & $31,713,278$ \\
\hline
\end{tabular}




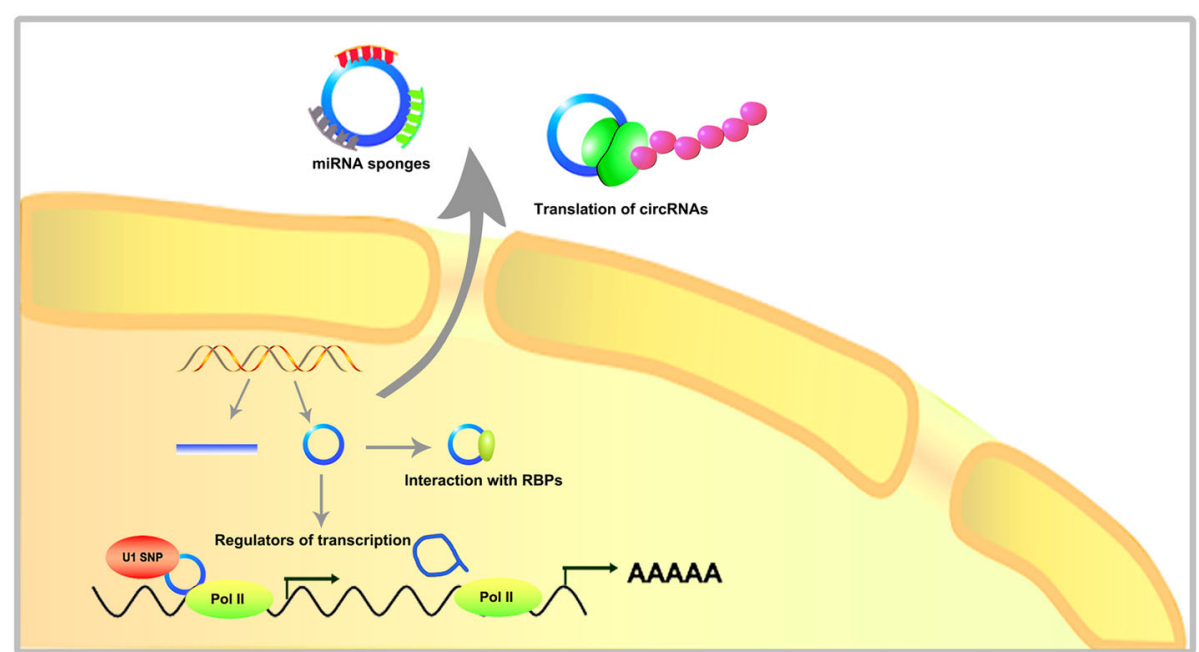

Fig. 3 Overview of the the mechanistic models of circRNAs

ZNF609), a functional circRNA expressed in mouse and human myoblasts, can translate proteins in mouse myoblasts driven by an internal ribosome entry site (IRES) [64]. This detection supplies the first determination that endogenous circRNAs exhibit protein-encoding abilities [64]. Later, the circRNA F-box and WD repeat domain containing 7 (circ-FBXW7) was found to be translated into the new $21 \mathrm{kDa}$ protein FBXW7 [65]. These discoveries indicate new capabilities for circRNAs and provide a new direction for the future of circRNA research.

\section{CircRNAs as modulators of the tumour microenvironment}

TME includes different cellular and non-cellular secreted components $[12,66]$. The cellular components of TME include CAEs, immune cells, CAFs, and CSCs [12, 66]. Secreted non cellular components comprise cytokines, growth factors, metabolites and ECM proteins $[12,66]$. There is an increasing mount of evidence showing the complex interaction between circRNAs and key counterparts in the TME. The importance and ubiquity of this interaction is just beginning to be realized, and warrant further investigation to develop new targets and cancer therapeutics. Here we are first systematically reviewing the interplay between circRNAs and cellular/ non-cellular counterparts of the TME. The communication mediated by circRNAs between tumour cells and the TME is shown in Fig. 4. The emerging role and mechanistic axis of circRNAs associated with the TME is listed in Table 2.

\section{CircRNAs and CAEs}

CAEs are an important component of the tumour stroma in the TME [12]. CAEs are arranged on the inner surface of tumour blood vessels and lymphatic vessels, and can be responsible for supporting blood vessel formation and tumour neovasculature [67]. It is widely believed that angiogenesis is an important mechanism by which tumours not only remove carbon dioxide and metabolic waste but also obtain adequate nutritional support [68]. Overexpression of various angiogenic factors and the rapid growth of tumour cells in the TME can lead to the development of vascular networks with many structural and functional abnormalities [69, 70]. Vascular endothelial growth factor (VEGF), which is amplified in various cancers, has been recognized to be essential for both physiological and pathological angiogenesis $[71,72]$. Moreover, targeting of inhibitors associated with PI3K/Akt signaling pathway can dramatically reduce the secretion of VEGF, leading to suppressive effects on angiogenesis [73]. CircRNAs involved in the TME can affect diverse physiological and pathological activities, including tumour angiogenesis $[17,74]$.

Most recently, Zou et al. identified the effects of circCDR1as on angiogenesis, with a positive correlation between circ-CDR1as and infiltrating level of CAEs [75]. Another research by Zhong et al. showed that circRNA myosin light chain kinase (circ-MYLK) could sponge miR-29a to relieve suppression for targeting VEGFA in breast cancer, thus promoting tumour angiogenesis [17]. This circ-MYLK-mediated ceRNA network would provide promising target for $\mathrm{BC}$ diagnosis and therapy [17]. Additionally, current evidence shows that circRNA SMARCA5 (circ-SMARCA5) can bind to serine and arginine rich splicing factor 1 (SRSF1) to regulate VEGFA pathway in glioblastoma multiforme (GBM) cells [16]. Specifically, SRSF1 can identify the proximal splice site (PSS) of VEGF, and elevate the expression of proangiogenic isoforms (VEGF-Axxxa), thus contributing to tumour angiogenesis [16]. 


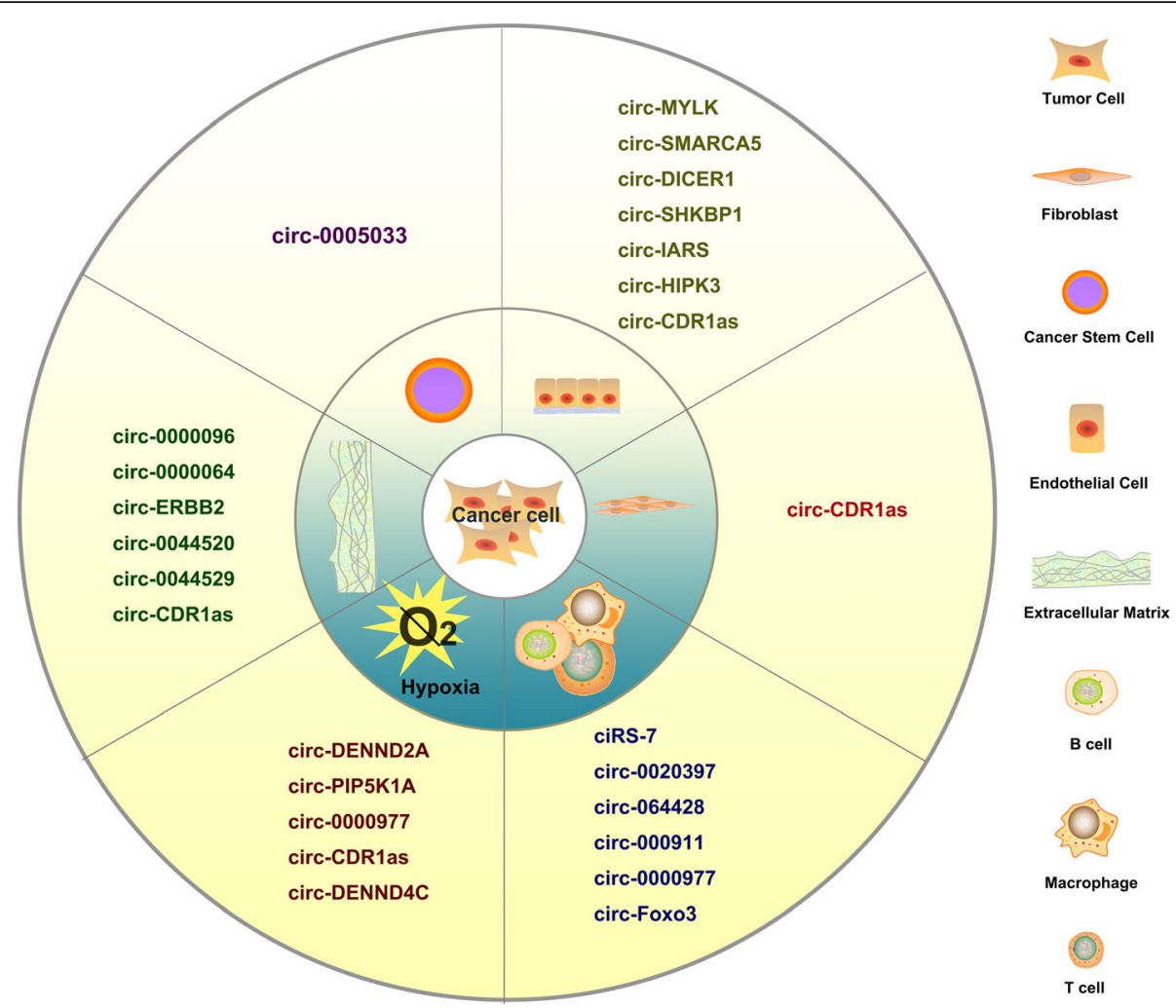

Fig. 4 The communication mediated by circRNAs between tumour cells and the TME

In addItion to VEGF, other angiogenic factors may also affect CAEs directly or indirectly [76-81]. Recent studies reveal that glioma-exposed endothelial cells (GECs) exhibit high expression of circRNA DICER1 (circ-DICER1) and its RBP MOV10 [82]. Of note, circDICER1 could sponge miR-103a-3p/miR-382-5p and attenuated the negative regulation of Zic family member 4 (ZIC4), thus mediating cell proliferation, migration and angiogenesis of GECs [82]. This molecular axis of MOV10/circ-DICER1/miR-103a-3p/miR-382-5p/ZIC4 gives novel insights into glioma angiogenesis, providing prospective targets for anti-angiogenesis strategy [82]. Another circRNA axises linked to glioma tumourigenesis and angiogenesis are the circ-SHKBP1/miR-544a/FOXP1 and circ-SHKBP1/miR-379/FOXP2 pathway [83]. It was shown that U87 GECs displayed high circ-SHKBP1 expression, and circ-SHKBP1 knockdown exhibited inhibitory effects on malignant phenotype and tube-formation capacities of GECs [83]. Specifically, FOXP1/FOXP2 can elevate the expression of angiogenic factor angio genic factor with G patch and FHA domains 1 (AGGF1), which can promote GEC activity, tube formation and migration through PI3K/AKT and extracellular signalregulated kinase $1 / 2(E R K 1 / 2)$ pathways [83]. It can be concluded that circ-SHKBP1-mediated regulatory axis may offer potential targets and molecular-based therapy for combined treatment of glioma [83].

Emerging studies have elucidated that aberrant expression of circRNAs can play oncogenic or anti-tumour functions in various cancers [31, 84]. Li et al. identified circRNA homeodomain interacting protein kinase 3 (circ-HIPK3) to be significantly decreased in $79.5 \%$ of the bladder cancer tissues and cell lines, revealing its underlying tumour-suppressive roles [85]. Interestingly, low circ-HIPK3 expression was positively associated with tumour grade, invasion, and the lymph node metastasis, suggesting its potential clinical value as a novel biomarker for early diagnosis and targeted therapy [85]. Mechanistically, circ-HIPK3 enrichment can abundantly sponge miR-558 to decrease heparanase (HPSE), VEGF, and matrix metallopeptidase 9 (MMP9) levels, thus effectively suppressing the invasive abilities and angiogenesis of bladder cancer cells [85]. Moreover, circRNA isoleucine-tRNA synthetase (circ-IARS) was detected to be increased in tissues and plasma exosomes of patients with pancreatic cancer (PC) [86]. PC cell-derived exosomal circ-IARS could be delivered to endothelial cell, enhancing vascular invasion [86]. Moreover, circ-IARS can also destory tight junctions between the endothelium cells, leading to increased permeability of vascular 


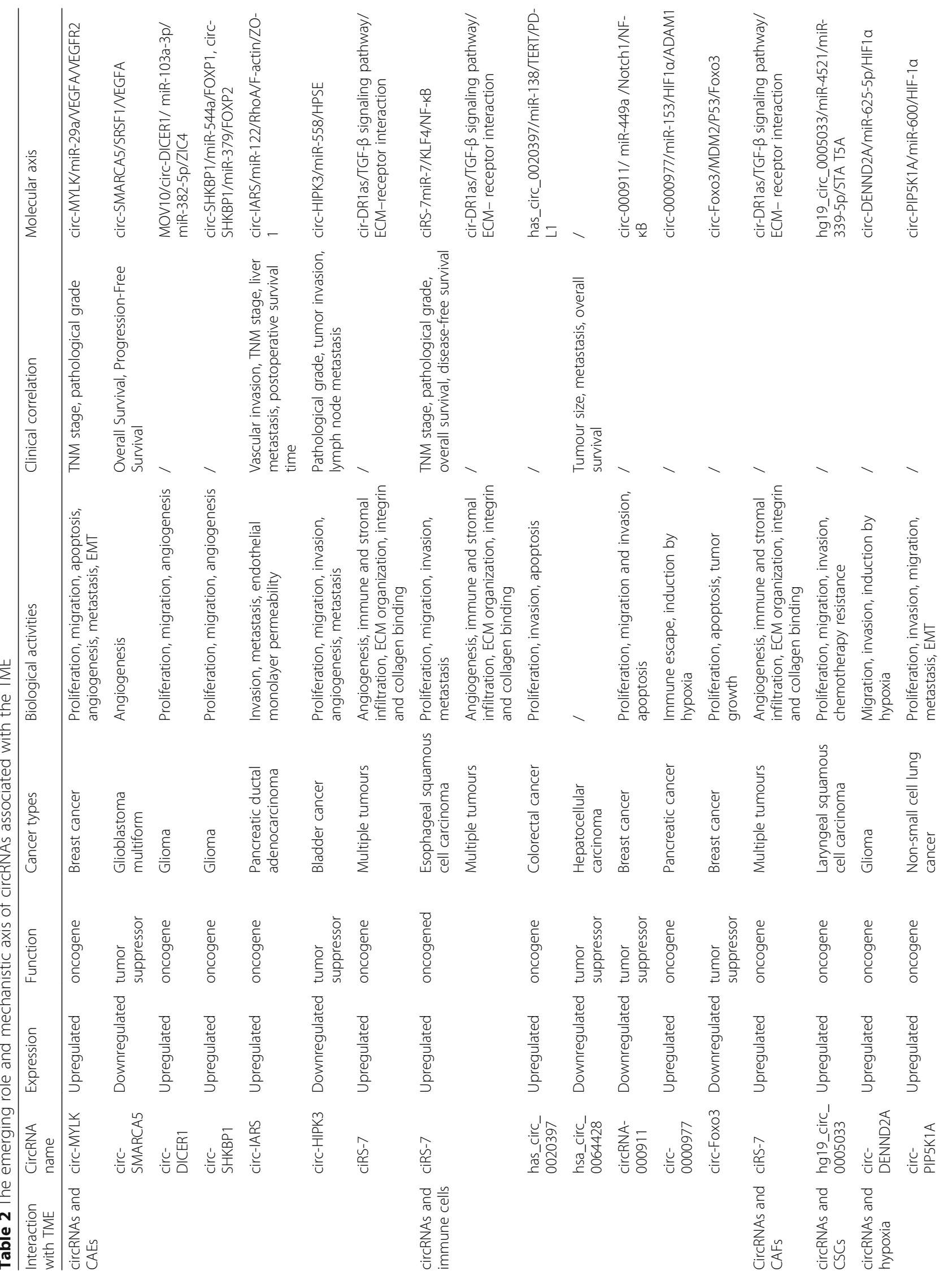




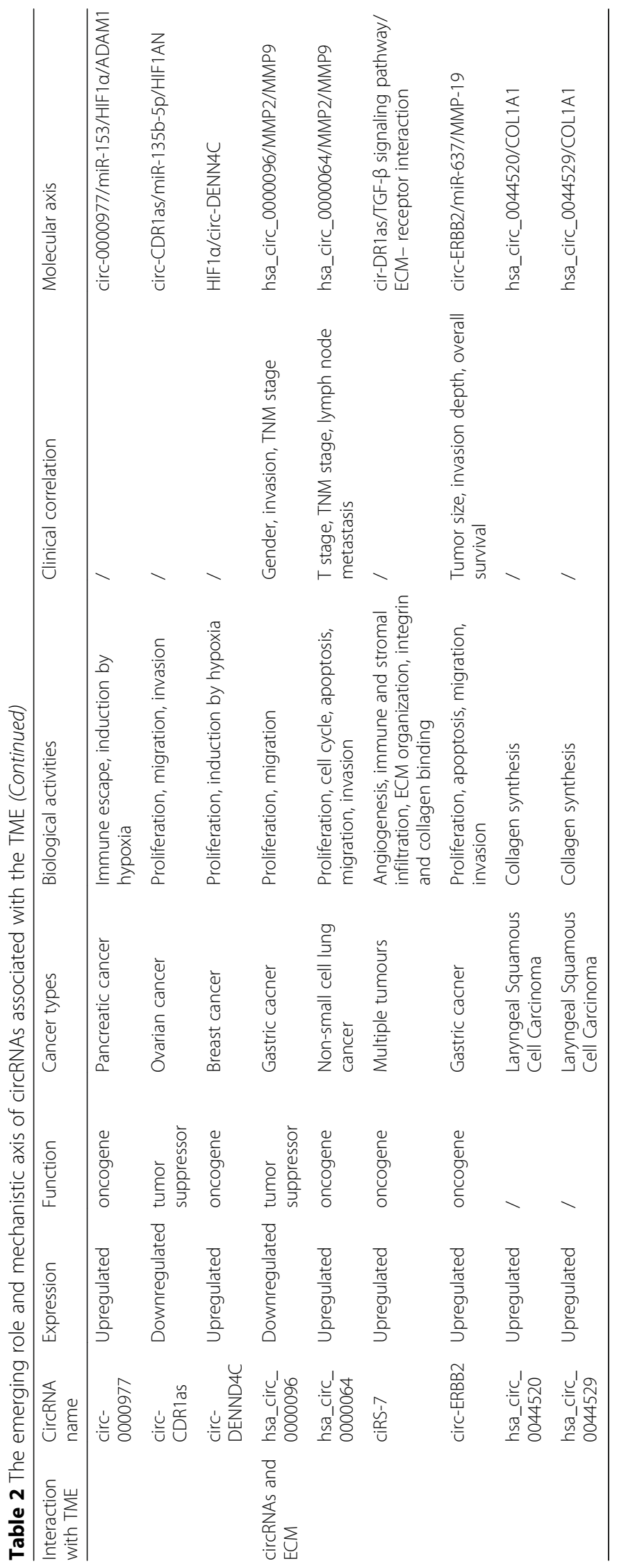


endothelial cells and tumour metastasis promotion [86]. Endothelial cells are critical for tumour angiogenesis, and the effects of circRNAs on endothelial cells can affect tumour progression. These findings remind us that targeting circRNAs in the CAEs may be a new approach to cancer therapy.

\section{CircRNAs and immune cells}

Immune cells, which represent the most abundant cellular component of the TME, have been a target of interest for their potent cytotoxic capabilities [87-89]. The crosstalk among cancer cells, immune cells as well as released factors may be involved in the regulation of tumour immunity, and establish an environment that facilitate cancer development and progression [90, 91]. Identifying key regulators within this crosstalk may provide prime candidates for therapeutic intervention [92, 93]. Recently, a variety of circRNAs associated with the TME are determined to be significantly dysregulated in various cancers [17, 83]. Moreover, some circRNAs have been found to interact with immune cells, providing the evidence for the role of circRNAs in the regulation of immune cells [94, 95].

\section{CircRNAs and macrophages}

It is known that mammalian macrophages can be mediated to various phenotypes under different external stimuli [96]. Current discovery revealed by Zhang et al. has provided the first evidence for the expression pattern of circRNAs in macrophage activation [97]. The expression pattern of circRNAs was explored in response to stimuli polarizing two distinct patterns of macrophage activation (M1 and M2) through circRNA microarray [97]. The validation assay indicated that high levels of circRNA003780, circRNA-010056 and circRNA-010231 were detected in M1 cells [97]. Similarly, the expression levels of circRNA-003424, circRNA-013630, circRNA-001489 and circRNA-018127 were also detected in M2 cells with fold-change $>5$ [97]. Differences in the expression of circRNAs in macrophages of different polarization states were confirmed, providing novel insight into the role of circRNAs in macrophage differentiation and polarization [97]. In addition, another study reported by Zou et al. showed that high level of circ-CDR1as predicted a higher ratio M2 macrophage, suggesting the oncogenic mechanism of circ-CDR1as in regulating the TME [75].

\section{CircRNAs and lymphocytes}

Multiple reports have elucidated that tumour infiltrating lymphocytes (TILs) display high proportion in the TME, contributing to better overall survivals $[98,99]$. It was demonstrated that HCC patients with higher percentage of TILs displayed better clinical outcomes, suggesting the prognostic value of TILs for HCC patients [100].
Then, Weng et al. performed global circRNA microarray between plasma of HCC patients with high TILs and low TILs [101]. Through validation assays, low hsa_circ 0064428 expression was found in HCC patients with high TILs and exhibited close correlation with overall survival, tumour size and metastasis in patients with HCC [101]. It can be concluded that hsa_circ_0064428 functioned as a novel immune-associated prognostic biomarker for HCC patients [101].

Programmed death-ligand 1/programmed death-1 (PDL1/PD-1), as key immune checkpoints, can suppress the activation of $\mathrm{T}$ lymphocytes and increase the immune tolerance of tumour cells, thereby achieving tumour immune escape [102-104]. Studies have increasingly shown that some circRNAs can induce PD-L1 expression in the TME and mediate the regulation of tumour immunity. Zhang et al. revealed that hsa_circ_0020397 was able to elevate the expression of PD-L1 and telomerase reverse transcriptase (TERT) by sequestering miR-138 in CRC cells [62]. Specifically, hsa_circ_0020397-mediated upregulation of PD-L1 can lead to the inhibition of apoptosis and acquisition of tumour immune escape in the TME [62]. The regulatory axis of hsa_circ_0020397/miR-138/TERT/PDL1 can help to further the theory of tumour immune escape and develop attractive strategies for CRC patients [62]. Shortly afterward, Du et al. reported the tumorsuppressive role of circ-Foxo3 in breast carcinoma [105]. According to histological analysis, the infiltration of Band $\mathrm{T}$ cells into the tumours and surrounding connective tissues expressed circ-Foxo3, suggesting an immune response of the hosts to the tumour xenografts [105].Current data provided by Zou et al. showed that circ-CDR1as takes an important role in immune cell infiltration in tumour tissues, especially those of CD8+ T cells [75]. Furthermore, abnormally expressed exosomal circRNAs may induce Treg cells, and directly interact with immune factors to mediate immune activity, achieving cell-to-cell communication [106, 107]. For instance, immune factors NF90/NF110 can activate circRNA production in the nucleus, and associate with mature circRNAs in the cytoplasm [94]. Upon viral infection, the depression of circRNA expression can be partly accounted by the nuclear export of NF90/NF110 to the cytoplasm [94]. The complex of NF90/NF110-circRNP accumulations can be found in the cytoplasm, and circRNAs can compete with viral mRNAs for binding to NF90/NF110, thus affecting host immune response [94]. Based on the studies above, circRNA may serve as a new tumour antigen, which may be induce the regulation of tumour immunity and develop a new cancer therapy.

\section{CircRNAs and immune-related molecules}

NF- $\mathrm{kB}$ is identified to mediate cellular stress responses, cytokines production, and the process of immune 
response $[108,109]$. The unique role of NF- $\mathrm{kB}$ has been indicated in tumour cells and immune cells, such as macrophages and dendritic cell (DCs) [109-111]. As we have mentioned, ciRS-7 has been reported to be abundant in ESCC [47]. Apart from this, inhibition of NF-kB can attenuate MMP-2 upregulation induced by ciRS-7, thus suppressing ciRS-7-mediated invasion of ESCC cells [51]. Another study reported by Wang et al. identified that NF- $\mathrm{kB}$ signaling is a functional target of circRNA000911/miR-449a axis, which may be partly responsible for the oncogenic activities in breast cancer cells [20]. To summarize, the network of circRNA-000911/miR$449 \mathrm{a} /$ Notch1/NF- $\mathrm{KB}$ may allow for a new direction of therapeutic strategy for breast cancer [20].

\section{CircRNAs and exosomes}

Exosomes specifically refer to discoidal vesicles with a diameter of $30-150 \mathrm{~nm}$, mediating the communication between immune cells and tumour cells [112, 113]. It is interesting to note that the circRNAs can specifically bind to tumour-specific miRNAs or mRNAs in exosomes, which can serve as new tumour antigens for regulating immune response [94]. Current studies show that a variety of circRNAs were obviously decreased in KRAS mutant cells and can be transferred to exosomes secreted from tumour cells [114].

\section{CircRNAs and Cancer stem cells}

CSCs, which are thought to be the origin of cancer cells, are the driving force for tumour growth, migration, metastasis and therapeutic resistance in multiple cancers [115-117]. It was found that CD133+ CD44+ CSCs (named TDP cells) isolated from the laryngeal squamous cell carcinoma (LSCC) cells could exert promotion effects on cell proliferation, migration, as well as resistance to chemotherapy and irradiation [118]. Moreover, stronger malignant behaviors can be observed in TDP cells compared with that in CD133+ or CD44+ LSCC stem cells, CD133-CD44- LSCC cells (named TDN cells), and parental TU-177 cells (named TPT cells) [118]. It is extremely worthwhile to determine the underlying mechanism of LSCC stem cells [118]. Therefore, Wu et al. uncovered that the core node of the circRNA-miRNAmRNA regulatory network that enriched in these biological processes and pathways might be important contributors of the enhanced malignancy of LSCC stem cells [118]. Specifically, hg19_circ_0005033 was determined to interact with miR-4521/miR-339-5p in LSCC stem cells, leading to upregulation of STAT5A, which can induce stem-like cell properties and the epithelialto-mesenchymal (EMT) transition in cancer $[118,119]$.

It can be concluded that the hg19_circ_0005033/miR4521/miR-339-5p/STAT5A axis supports the malignant features of LSCC stem cells [118]. The investigation of
circRNAs in the regulation of CSCs would give new insights into the molecular mechanisms of CSCs, and provide potential biomarkers and targets for cancer patients.

\section{CircRNAs and CAFs}

CAFs are fibroblasts in a state of continuous activation [120]. As one of the most important components of mesenchyme, CAFs play an important role in tumour growth, proliferation and metastasis [120, 121]. In turn, tumour cells can promote fibroblast activation through feedback regulation [122]. Recent studies have revealed that circRNAs can be found in the normal fibroblasts (NFs). Du et al. reported that hsa_circ_0001946, which was obviously upregulated in lung cancer tissues, was also confirmed to be highly-expressed in the human normal lung fibroblasts MRC-5, compared with that of human NSCLC cell line A549 [123]. Further research validated that hsa_circ_0001946 suppressed progression and induced cisplatin sensitivity in A549 cells, which indirectly provide the basis of interaction between hsa circ_0001946 and CAFs [123]. In addition, Du et al. revealed that the level of circ-Foxo3 was significantly reduced in NIH3T3 and MEF fibroblasts compared with cancer cell lines [58]. Interestingly, NIH3T3 fibroblasts treated with cell proliferating factor Epidermal growth factor (EGF) displayed decreased circ-Foxo3 expression [58]. Correspondingly, the level of circ-Foxo3 exhibited obvious elevation when the cells are treated with EGF inhibitor AG1478 [58].

Mounting studies have revealed that dysregulation of miRNAs and exosomal miRNAs can interact with the CAFs and participate in the regulation of secretory phenotype, tumourigenesis, metastatic progression, drug resistance and poor prognosis [124-126]. And it is commonly known that circRNAs can function as miRNA sponges to function in various cancers $[9,85]$. Thus, it can be inferred that the axis of circRNA/miRNA can be involved in the TME through interacting with CAFs. A recent research by Zou et al. identified a positive correlation between circ-CDR1as expression and the infiltrating level of CAFs [75]. It was shown that circ-CDR1as may serve as a miRNA sponge to form a ceRNA network, thus mediating the TME [75]. The breakthrough in this attractive field may pave a new path for cancer patients based on the targeted therapy against CAFs.

\section{CircRNAs and extracellular matrix}

ECM, including collagen, fibronectin, laminin, glycosaminoglycans and proteoglycans, is an important tissue barrier for tumour invasion and metastasis [127, 128]. MMPs are involved in the turnover and remodeling of ECM and serve as key regulators in the pathological destruction of various tumours [129-131]. Hsa_circ 
0000096 knockdown was reported to suppress GC cell migration and invasion through decreasing MMP-2 and MMP-9 expression [132]. Moreover, aberrant expression of hsa_circ_0000096 was closely associated with tumour invasion, TNM stage and gender, revealing its potential utility as prospective markers [132]. A similar research showed that high level of hsa_circ_0000064 was positively correlated with $\mathrm{T}$ stage, TNM stage, and lymphatic metastasis in NSCLC patients, and promoted NSCLC cell migration and invasion partly through regulating MMP2/MMP9 expression [133]. Furthermore, Li et al. revealed that upregulation of circ-ERBB2 predicts unfavorable prognosis and activates GC progression partly through miR-637/MMP-19 and miR-503/CACUL1 pathway [134].

Currently, some circRNAs are demonstrated to be involved in the ECM regulation. Zou et al. reported that circ-CDR1as participates in the regulation of ECM organization, integrin binding, and collagen binding [75]. Pathway analysis further identified the involvement of circ-CDR1as in ECM-receptor interaction [75]. In addition, Fan et al. identified 21 dysregulated circRNAs associated with collagen formation in human LSCC tissues through analysing circRNA profiling data [135]. Among these host genes, hsa_circ_0044520 and hsa circ_0044529 are hosted in the collagen type I alpha 1 chain (COL1A1) gene, which can encode the subunit of type I collagen and regulate the tumourigenesis of various cancers [135]. These interactions may further the identification of ECM in the TME and allow for more opportunities for patients [135]. However, the interplay between circRNAs and ECM still requires extensive investigation.

\section{CircRNAs and hypoxia}

Cancer cells and stromal cells in the TME often limit the access to nutrients and oxygen, contributing to a hypoxia environment [136, 137]. Hyperpoic-inducible factor $1 \alpha(\mathrm{HIF} 1 \alpha)$, a hallmark of hypoxia, exerts great influences on cancer pathobiology [138, 139]. Recently, hypoxia-activated circ-DENND2A was revealed to promote the migratory and invasive capacities of glioma cells through competitively binding to miR-625-5p [55]. $\mathrm{Su}$ et al. further showed that circ-DENND2A was dramatically increased in glioma tissues with high level of HIF1 $\alpha$ [55]. Moreover, another study showed that the circ-0000977 level can be induced by hypoxia in pancreatic cancer cells [140]. The axis of circ-0000977/miR153 can mediate HIF1 $\alpha$-induced immune escape of pancreatic cancer cells through targeting HIF1 $\alpha /$ ADAM10 [140]. Similarly, Chi et al. demonstrated that circ-PIP5K1A/miR-600/HIF1 $\alpha$ axis prompted NSCLC proliferation and metastasis and offer potential targets for NSCLC patients [53]. In ovarian cancer, circ-CDR1as was significantly lower in tumour tissues, and functioned as a sponge of miR-135b-5p to increase the expression of hypoxia-inducible factor 1-alpha inhibitor (HIF1AN), thus exerting inhibitory role on proliferation capacity of ovarian cancer cells [141]. In addition, Liang et al. reported that circ-DENND4C, a HIF1 $\alpha$-associated circRNA, was able to promote the proliferation of breast cancer cells under hypoxia [142]. Importantly, high circDENND4C level was positively correlated with larger tumour size in breast cancer patients [142]. Understanding the mechanism of circRNAs under hypoxia may provide further evidence for the potential utilities of circRNAs.

\section{The potential of circRNAs as prospective biomarkers or targets in cancer clinics}

Current studies have shown the great potential of circRNAs as novel biomarkers. Unlike linear RNA molecules, circRNAs possess covalently closed loop structures with high stabilities, avoiding degradation induced by exonuclease RNaseR [143]. Moreover, circRNAs can be detected in tissue samples, saliva or plasma with cellspecific or stage-specific expression pattern [144]. These characteristics can partly account for the possible application of circRNAs as prospective biomarkers. Hsiao et al. found that circCCDC66 was obviously increased in CRC tissues and its amplification predicted poor prognosis for patients with CRC [84]. Further analysis of the receiver operating characteristic (ROC) curve demonstrated that circCCDC66 may be diagnostic biomarker for CRC patients [84]. Another study by Wang et al. detected the elevated circSETDB1 expression in serous ovarian cancer (SOC) patients [145]. It is worth noting that high level of serum circSETDB1 can distinguish SOC patients from healthy individuals [145]. The serum circSETDB1 may become a prospective non-invasive biomarker for SOC patients [145]. Interestingly, circRNAs are stably overexpressed in exosomes, such as circ-RASSF2, circ-PTGR1 and circ-IARS [86, 146, 147]. For instance, $\mathrm{Li}$ et al. demonstrated the high level of exosomal circ-IARS in pancreatic cancer tissues and plasma exosomes, suggesting the diagnostic value of exosomal circ-IARS as a promising biomarker [86]. To summarize, circRNAs may have a potential to be developed into effective biomarkers.

An increasing number of studies have highlighted circRNAs as oncogenic or tumour-suppressive regulators in multiple cancers [33, 148, 149]. Nowadays, studies have focused on the application of circRNAs as therapeutic targets $[10,62]$. The effective techniques of gene knockdown or overexpression may shed new light on the targeting of circRNAs. For oncogenic circRNAs, specific siRNAs or shRNAs targeting the back-splice junction, which can avoid the interference of homologous 
linear mRNA expression, were used to achieve circRNAspecific knockdown [150]. Additionally, CRISPR-Cas13a, a flexible platform, was applied to implement programmable knockdown with reduced off-target impacts [151]. As for intron circularized circRNAs, complementary paired siRNAs were designed targeting intron region sequences to disrupt RNA formation, leading to circRNA knockdown [152]. For tumoursuppressive circRNAs, the overexpression vectors prompting back-splicing comprised circRNA-forming exons and flanking introns with reverse complementary sequences [3]. The implication of cis strategy can offer an accurate approach to study the target gene [153]. The replacement of the original weak promoter or a weak intronic RNA with a corresponding strong counterpart can facilitate amplification of circRNAs [153]. To summarize, circRNAs show great potential as therapeutic targets and targeting of circRNAs may become a new model for future cancer treatment. However, extensive work should be done to develop advanced techniques and effective drugs targeting circRNAs.

\section{circRNAs as novel targets reversing drug resistance for cancer therapeutics}

Drug resistance is a huge obstacle of the treatment of tumours, and circRNAs are important players in regulating drug resistance [154]. The emerging role and mechanistic axis of circRNAs associated with drug resistance is shown in Table 3. Liu et al. found that circRNA-MTO1 can interact with tumour necrosis factor receptor associated factor 4 (TRAF4) to decrease Eg5 protein, thereby reversing the resistance to monastrol in breast cancer cells [155]. Another research of breast cancer showed that knockdown of circ-0006528 can obviously increase the sensitivity of Adriamycin (ADM)-resistant cell lines to ADM [148]. Through RNA-seq and bioinformatic analysis, Zhu et al. identified 80 significantly altered circRNAs in osteosarcoma (OS), which may closely associated with chemotherapy resistance [156]. It was confirmed that hsa-circ-0001258/hsa-miR-744-3p/glutathione S-transferase mu 2 (GSTM2) axis suppressed the Doxorubicin (DXR) resistance of OS cells [156]. In addition, circ-PVT1 knockdown was found to weaken the resistance to doxorubicin and cisplatin of OS cells through decreasing the expression of classical drug resistance-related gene ABCB1 [157]. As for the chemoradiation resistance in $\mathrm{CRC}$, Xiong et al. investigated circRNA profiles in CRC cells with resistance to 5fluorouracil- (5-FU) [158]. Microarray analysis showed that 47 circRNAs were significantly increased and 24 circRNAs were dereased in 5-FU resistant CRC cells, with fold change $>2$ [158]. Intriguingly, Xiong et al. also speculated the regulatory axis of hsa_circ_0000504/hsamiR-485-5p/STAT3 in CRC and downregulation of hsa circ_0000504 would be a possible option to overcome 5FU resistance in CRC [158]. The establishment of this database may be useful to discover effective targets to overcome drug resistance of CRC cells [158]. Recently, Shang et al. found a detailed circPAN3/miR-153-5p/ miR-183-5p/X-linked inhibitor of apoptosis protein (XIAP) interaction in AML, which can be used as a novel target for reversing ADM resistance in AML patients [159]. However, extensive studies are urgently needed to further the understanding of circRNAsassociated drug resistance in various cancers.

EGFR TKIs, as the first-line treatment for patients with EGFR mutations, includes gefitinib, erlotinib, and afatinib [160]. However, many patients developed resistance to EGFR TKIs within about 1-2 year after therapy, which largely limited the long-term efficacy of drug and was unfavorable for patients' prognosis [161]. Recently, Zhou et al. reported that hsa_circ_0004015, a highlyexpressed circRNA in NSCLC tissues, can act as a miR1183 sponge to regulate 3-phosphoinositide dependent protein kinase 1 (PDPK1), thereby increasing the resistance of NSCLC cells to gefitinib [54]. Moreover, Chen et al. firstly revealed comprehensive analysis of circRNA profiling in EGFR-TKI inhibitor AZD9291-resistant NSCLC cells [162]. A total of 15,504 circRNAs were significantly dysregulated (With $\mid$ fold change $\mid \geq 2$ and $p<0.05$ ), including 7966 upregulated and 7538 downregulated circRNAs [162]. It was predicted that hsa_circ 0043632 mediates NSCLC progression and AZD9291resistance of NSCLC cells through miR-492/TIMP metallopeptidase inhibitor 2 (TIMP2) axis [162]. However, further research should be conducted to verify this prediction from bioinformatic analysis.

\section{Future prospective and conclusion}

CircRNAs were initially thought to be functionless byproducts of aberrant RNA splicing [1]. The mystery of circRNAs has gradually been unveiled owing to the implication of high-throughput screening technology [39, 163]. A variety of circRNAs have been reported to mediate cancer occurrence and progression through various molecular mechanism, such as acting as miRNA sponges, interacting with RBPs, and regulating expression of parental genes [43, 82, 141].

Despite much advances in the research of circRNAs, there is still a long way ahead for circRNAs to be incorporated into clinical practice. Firstly, it is essential to develop a standard naming rule of circRNAs and perfect the building of the databases of circRNAs. The majority of circRNAs are named on the basis of their host genes or functions, and the condition is easily confused when several circRNAs arise from the same host gene or more than one circRNAs with relevant roles [64, 164]. Recently, Circbank, a comprehensive database, collects 140, 


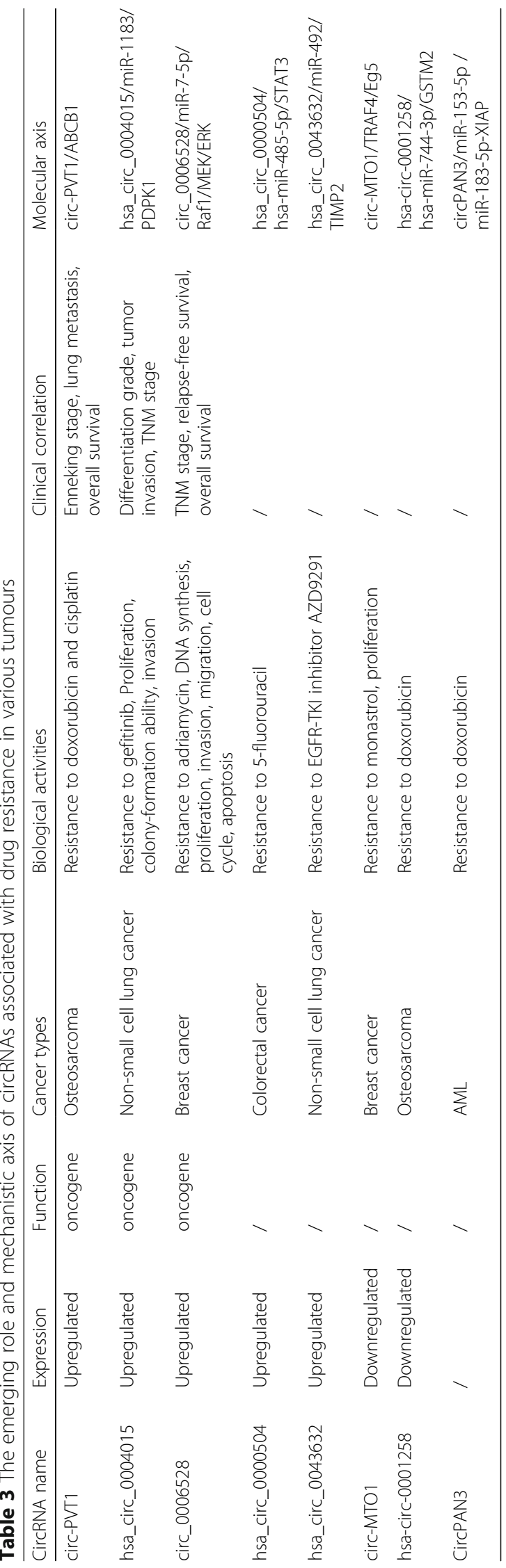


790 human circRNAs with standard nomenclature, which can solve the conflicts caused by previous naming rules. Moreover, Circbank also introduces five critical features of circRNAs, including m6A modification of circRNAs, mutation of circRNAs, miRNA binding site, conservation of circRNAs, and protein-coding potential of circRNAs, giving superior to the design of CircBase, Circ2Traits, CircRNADb and CicrNet databases [165-169]. However, the addition of circRNAs of other species in Circbank dataset is in an urgent need [165].

For a century, the somatic mutation theory (SMT) has been the prevalent theory to explain carcinogenesis [170]. More recently, alternative theories have been introduced, such as tissue organization field theory (TOFT) [171]. The TME involves the coevolution of both cancerous cells and the surrounding stroma. The crosstalk between circRNAs and critical components of the TME can mediate tumourigenesis, angiogenesis, immune response, and metastatic progression. This new perspective on cancer research is different from the view of SMT that cancer is a cellular problem. The involvements of circRNAs in the TME may help us to rethink cancer progress and provide new approach for therapeutic use in cancer $[16,17,118]$.

Moreover, larger tissue samples, longer follow-up visits, as well as the conduction of in-vivo assays are proposed to unveil the identification of circRNAs and improve the development of the molecular diagnosis. Exosomes have emerged as a novel approach for the treatment and diagnosis of cancer after RNA content was discovered in exosomes [172]. The stable expression of circRNAs in the exosomes and blood plasma may pave a new path for cancer diagnosis and treatment. However, considerable work is needed to solve the difficulties and defects of circRNA-based daignosis, such as high expense, existence of secondary structure, and limited knowledge of mechanism.

In this review, we briefly summarize the biogenesis, characteristics, classification and regulatory mechanism of circRNAs in various cancers. More importantly, we are first reviewing the interplay between circRNAs and key components of the TME, and further discussing their potential clinical value as biomarkers and the challenges of future research of circRNAs.

\footnotetext{
Abbreviations

5-Fu: 5-Fluorouracil; ADM: Adriamycin; AGGF1: Angiogenic factor with g patch and fha domains 1; Ago2: Argonaut 2; CAEs: Cancer-associated endothelial cells; CAFs: Cancer-ssociated fibroblasts; CDK2: Cyclin dependent kinase 2; ceRNA: Competitive endogenous RNA; ChIP: Chromatin immunoprecipitation; CircRNAs : Circular RNAs; CIRI: CircRNA identification; ciRNAs: Circular intron RNAs; COL1A1: Collagen type I alpha 1 chain; CRC: Colorectal cancer; CSCs: Cancer stem cells; DXR: Doxorubicin; ecircRNAs: Exon circRNAs; eiciRNAs: Exon-intron circRNAs; EMT: Epithelial-tomesenchymal; ERK: Extracellular signal-regulated kinase; ESCC: Esophageal squamous cell carcinoma; FGF: Fibroblast growth factor; GBM: Glioblastoma multiforme; GC: Gastric cancer; GSTM2: Glutathione S-transferase mu 2;
}

HCC: Hepatocellular carcinoma; HEGF: Human epidermal growth factor; HIF1AN: Hypoxia-inducible factor 1-alpha inhibitor; HIF1a: Hyperpoicinducible factor 1a; IRES: Internal ribosome entry site; IncRNA: Long noncoding RNAs; MDR: Multidrug response; ncRNAs : Non-coding RNAs; NSCLC: Non-small cell lung cancer; ORF: Open reading frame; OS: Osteosarcoma; PDK1: Pyruvate dehydrogenase kinase; PD-

L1: Programmed death ligand 1; PDPK1: 3-phosphoinositide dependent protein kinase 1; PI3K: Phosphatidylinositol 3-kinase; PSS: Proximal splice site; PTEN: Phosphatase and tensin homolog; qRT-PCR: Quantitative reverse transcription polymerase chain reaction; RBP: RNA-binding protein; RNAseq: RNA-sequencing; RNA-seq: RNA-sequencing; STAT3: Signal transducer and activator of transcription 3; TERT: Telomerase reverse transcriptase; TILs: Tumour-infifiltrating lymphocytes; TIMP2: TIMP metallopeptidase inhibitor 2; TME: Tumour microenvironment; TRAF4: Tumour necrosis factor receptor associated factor 4; TSP-1: Thrombospondin 1; VEGF: Vascular endothelial growth factor

\section{Acknowledgements}

Not applicable.

\section{Author's contribution}

$\mathrm{MZH}, \mathrm{SY}$ and GXY provided the detection of the manuscript. MZH and SY wrote and edited the manuscript. SY and GXY drew the figures and tables. WXZ and JJF provided the guidance throughout the preparation of this manuscript.

\section{Funding}

The work was supported by the Innovation Fund for Outstanding Doctoral Candidates of Peking University Health Science Center (Grant number: 71013Y2029).

\section{Availability of data and materials \\ Not applicable.}

Ethics approval and consent to participate

Not applicable.

\section{Consent for publication}

Not applicable.

\section{Competing interests}

The authors declare that they have no competing interests.

\section{Author details}

${ }^{1}$ Key Laboratory of Carcinogenesis and Translational Research (Ministry of Education), Division of Gastrointestinal Cancer Translational Research Laboratory, Peking University Cancer Hospital \& Institute, Beijing, People's Republic of China. ${ }^{2}$ Department of Gastrointestinal Surgery, Peking University Cancer Hospital, Beijing, People's Republic of China. ${ }^{3}$ Department of Medical Oncology, Jiangsu Cancer Hospital, Jiangsu Institute of Cancer Research, The Affiliated Cancer Hospital of Nanjing Medical University, Nanjing, Jiangsu, People's Republic of China.

Received: 26 August 2019 Accepted: 2 December 2019

Published online: 14 January 2020

\section{References}

1. Chen LL. The biogenesis and emerging roles of circular RNAs. Nat Rev Mol Cell Biol. 2016;17:205-11.

2. Zhang Y, Xue W, Li X, Zhang J, Chen S, Zhang JL, Yang L, Chen LL. The biogenesis of nascent circular RNAs. Cell Rep. 2016;15:611-24.

3. Li X, Yang L, Chen LL. The biogenesis, functions, and challenges of circular RNAs. Mol Cell. 2018:71:428-42.

4. Kun-Peng Z, Xiao-Long M, Lei Z, Chun-Lin Z, Jian-Ping H, Tai-Cheng Z. Screening circular RNA related to chemotherapeutic resistance in osteosarcoma by RNA sequencing. Epigenomics-UK. 2018;10:1327-46.

5. Hsu MT, Coca-Prados M. Electron microscopic evidence for the circular form of RNA in the cytoplasm of eukaryotic cells. Nature. 1979;280:339-40.

6. Lopez-Jimenez E, Rojas AM, Andres-Leon E. RNA sequencing and prediction tools for circular RNAs analysis. Adv Exp Med Biol. 2018;1087:17-33. 
7. Hansen TB, Kjems J, Damgaard CK. Circular RNA and miR-7 in cancer. Cancer Res. 2013;73:5609-12.

8. Salzman J, Chen RE, Olsen MN, Wang PL, Brown PO. Cell-type specific features of circular RNA expression. PLoS Genet. 2013;9:e1003777.

9. Wang R, Zhang S, Chen X, Li N, Li J, Jia R, Pan Y, Liang H. CircNT5E acts as a sponge of miR-422a to promote Glioblastoma tumorigenesis. Cancer Res. 2018;78:4812-25

10. Zhao W, Dong M, Pan J, Wang Y, Zhou J, Ma J, Liu S. Circular RNAs: a novel target among noncoding RNAs with potential roles in malignant tumors (review). Mol Med Rep. 2019;20:3463-74.

11. Belli C, Trapani D, Viale G, D'Amico P, Duso BA, Della VP, Orsi F, Curigliano G. Targeting the microenvironment in solid tumors. Cancer Treat Rev. 2018;65:22-32.

12. Quail DF, Joyce JA. Microenvironmental regulation of tumor progression and metastasis. Nat Med. 2013;19:1423-37.

13. Ringuette GC, Bernard G, Tremblay S, Chabaud S, Bolduc S, Pouliot F. Exosomes induce fibroblast differentiation into cancer-associated fibroblasts through TGFbeta signaling. Mol Cancer Res. 2018;16:1 196-204.

14. Allegrezza MJ, Conejo-Garcia JR. Targeted therapy and immunosuppression in the tumor microenvironment. Trends Cancer. 2017;3:19-27.

15. Patel A, Sant S. Hypoxic tumor microenvironment: opportunities to develop targeted therapies. Biotechnol Adv. 2016;34:803-12.

16. Barbagallo D, Caponnetto A, Brex D, Mirabella F, Barbagallo C, Lauretta G, Morrone A, Certo F, Broggi G, Caltabiano R, et al. CircSMARCA5 regulates VEGFA mRNA splicing and angiogenesis in glioblastoma multiforme through the binding of SRSF1. Cancers (Basel). 2019;11:E194.

17. Zhong Z, Huang M, Lv M, He Y, Duan C, Zhang L, Chen J. Circular RNA MYLK as a competing endogenous RNA promotes bladder cancer progression through modulating VEGFANEGFR2 signaling pathway. Cancer Lett. 2017;403:305-17.

18. Shang $Q$, Yang Z, Jia R, Ge $S$. The novel roles of circRNAs in human cancer. Mol Cancer. 2019;18:6.

19. Arnaiz E, Sole C, Manterola L, Iparraguirre L, Otaegui D, Lawrie CH. CircRNAs and cancer: biomarkers and master regulators. Semin Cancer Biol. 2019;58:90-9.

20. Wang H, Xiao Y, Wu L, Ma D. Comprehensive circular RNA profiling reveals the regulatory role of the circRNA-000911/miR-449a pathway in breast carcinogenesis. Int J Oncol. 2018:52:743-54.

21. Jeck WR, Sorrentino JA, Wang K, Slevin MK, Burd CE, Liu J, Marzluff WF, Sharpless NE. Circular RNAs are abundant, conserved, and associated with ALU repeats. Rna. 2013;19:141-57.

22. Memczak S, Jens M, Elefsinioti A, Torti F, Krueger J, Rybak A, Maier L, Mackowiak SD, Gregersen LH, Munschauer M, et al. Circular RNAs are a large class of animal RNAs with regulatory potency. Nature. 2013;495:333-8.

23. Guo JU, Agarwal V, Guo H, Bartel DP. Expanded identification and characterization of mammalian circular RNAs. Genome Biol. 2014;15:409.

24. Wang F, Nazarali AJ, Ji S. Circular RNAs as potential biomarkers for cancer diagnosis and therapy. Am J Cancer Res. 2016;6:1167-76.

25. Li Z, Huang C, Bao C, Chen L, Lin M, Wang X, Zhong G, Yu B, Hu W, Dai L, et al. Exon-intron circular RNAs regulate transcription in the nucleus. Nat Struct Mol Biol. 2015:22:256-64

26. Zhang $Y$, Zhang $X O$, Chen T, Xiang JF, Yin QF, Xing YH, Zhu S, Yang L, Chen LL. Circular intronic long noncoding RNAs. Mol Cell. 2013;51:792-806.

27. Suzuki H, Tsukahara T. A view of pre-mRNA splicing from RNase $R$ resistant RNAs. Int J Mol Sci. 2014;15:9331-42.

28. Salzman J, Gawad C, Wang PL, Lacayo N, Brown PO. Circular RNAs are the predominant transcript isoform from hundreds of human genes in diverse cell types. PLoS One. 2012;7:e30733.

29. Rybak-Wolf A, Stottmeister C, Glazar P, Jens M, Pino N, Giusti S, Hanan M, Behm M, Bartok O, Ashwal-Fluss R, et al. Circular RNAs in the mammalian brain are highly abundant, conserved, and dynamically expressed. Mol Cell. 2015:58:870-85.

30. Wang PL, Bao Y, Yee MC, Barrett SP, Hogan GJ, Olsen MN, Dinneny JR, Brown PO, Salzman J. Circular RNA is expressed across the eukaryotic tree of life. PLoS One. 2014;9:e90859.

31. Yu J, Xu QG, Wang ZG, Yang Y, Zhang L, Ma JZ, Sun SH, Yang F, Zhou WP. Circular RNA cSMARCA5 inhibits growth and metastasis in hepatocellular carcinoma. J Hepatol. 2018;68:1214-27.

32. Chen L, Zhang S, Wu J, Cui J, Zhong L, Zeng L. Ge S: circRNA_100290 plays a role in oral cancer by functioning as a sponge of the miR-29 family. Oncogene. 2017;36:4551-61.
33. Yang $R$, Xing $L$, Zheng $X$, Sun $Y$, Wang $X$, Chen J. The circRNA circAGFG1 acts as a sponge of miR-195-5p to promote triple-negative breast cancer progression through regulating CCNE1 expression. Mol Cancer. 2019;18:4.

34. Wang L, Long H, Zheng Q, Bo X, Xiao X, Li B. Circular RNA circRHOT1 promotes hepatocellular carcinoma progression by initiation of NR2F6 expression. Mol Cancer. 2019;18:119.

35. Yi YY, Yi J, Zhu X, Zhang J, Zhou J, Tang X, Lin J, Wang P, Deng ZQ. Circular RNA of vimentin expression as a valuable predictor for acute myeloid leukemia development and prognosis. J Cell Physiol. 2019;234:3711-9.

36. Liu J, Kong F, Lou S, Yang D, Gu L. Global identification of circular RNAs in chronic myeloid leukemia reveals hsa_circ_0080145 regulates cell proliferation by sponging miR-29b. Biochem Biophys Res Commun. 2018; 504:660-5.

37. Meng S, Zhou H, Feng Z, Xu Z, Tang Y, Li P, Wu M. CircRNA: functions and properties of a novel potential biomarker for cancer. Mol Cancer. 2017;16:94.

38. Verduci L, Strano S, Yarden Y, Blandino G. The circRNA-microRNA code: emerging implications for cancer diagnosis and treatment. Mol Oncol. 2019; 13:669-80.

39. $X u H$, Wang $C$, Song $H$, Xu Y, Ji G. RNA-Seq profiling of circular RNAs in human colorectal cancer liver metastasis and the potential biomarkers. Mol Cancer. 2019;18:8.

40. Zheng Q, Bao C, Guo W, Li S, Chen J, Chen B, Luo Y, Lyu D, Li Y, Shi G, et al. Circular RNA profiling reveals an abundant circHIPK3 that regulates cell growth by sponging multiple miRNAs. Nat Commun. 2016;7:11215.

41. Abdelmohsen K, Panda AC, Munk R, Grammatikakis I, Dudekula DB, De S, Kim J, Noh JH, Kim KM, Martindale JL, Gorospe M. Identification of HuR target circular RNAs uncovers suppression of PABPN1 translation by CircPABPN1. RNA Biol. 2017;14:361-9.

42. Li Z, Huang C, Bao C, Chen L, Lin M, Wang X, Zhong G, Yu B, Hu W, Dai L, et al. Corrigendum: exon-intron circular RNAs regulate transcription in the nucleus. Nat Struct Mol Biol. 2017;24:194.

43. Pamudurti NR, Bartok O, Jens M, Ashwal-Fluss R, Stottmeister C, Ruhe L, Hanan M, Wyler E, Perez-Hernandez D, Ramberger E, et al. Translation of CircRNAs. Mol Cell. 2017;66:9-21.

44. Lu LF, Gasteiger G, Yu IS, Chaudhry A, Hsin JP, Lu Y, Bos PD, Lin LL, Zawislak CL, $C h o S$, et al. A single miRNA-mRNA interaction affects the immune response in a context- and cell-type-specific manner. Immunity. 2015;43:52-64.

45. Wang CJ, Zhu CC, Xu J, Wang M, Zhao WY, Liu Q, Zhao G, Zhang ZZ. The IncRNA UCA1 promotes proliferation, migration, immune escape and inhibits apoptosis in gastric cancer by sponging anti-tumor miRNAs. Mol Cancer. 2019;18:115.

46. Song $Y X$, Sun JX, Zhao JH, Yang YC, Shi JX, Wu ZH, Chen XW, Gao P, Miao ZF, Wang ZN. Non-coding RNAs participate in the regulatory network of CLDN4 via ceRNA mediated miRNA evasion. Nat Commun. 2017:8:289.

47. Zheng $X B$, Zhang $M, X u M Q$. Detection and characterization of ciRS-7: a potential promoter of the development of cancer. Neoplasma. 2017;64:321-8.

48. Hansen $\mathrm{TB}$, Jensen $\mathrm{Tl}$, Clausen BH, Bramsen JB, Finsen B, Damgaard CK, Kjems J. Natural RNA circles function as efficient microRNA sponges. Nature. 2013:495:384-8.

49. Pan H, Li T, Jiang Y, Pan C, Ding Y, Huang Z, Yu H, Kong D. Overexpression of circular RNA ciRS-7 abrogates the tumor suppressive effect of miR-7 on gastric cancer via PTEN/PI3K/AKT signaling pathway. J Cell Biochem. 2018; 119:440-6.

50. Sang M, Meng L, Sang Y, Liu S, Ding P, Ju Y, Liu F, Gu L, Lian Y, Li J, et al. Circular RNA ciRS-7 accelerates ESCC progression through acting as a miR876-5p sponge to enhance MAGE-A family expression. Cancer Lett. 2018; 426:37-46.

51. Huang H, Wei L, Qin T, Yang N, Li Z, Xu Z. Circular RNA ciRS-7 triggers the migration and invasion of esophageal squamous cell carcinoma via miR-7/ KLF4 and NF-kappaB signals. Cancer Biol Ther. 2019;20:73-80.

52. Li RC, Ke S, Meng FK, Lu J, Zou XJ, He ZG, Wang WF, Fang MH. CiRS-7 promotes growth and metastasis of esophageal squamous cell carcinoma via regulation of miR-7/HOXB13. Cell Death Dis. 2018:9:838.

53. Chi Y, Luo $Q$, Song $Y$, Yang F, Wang $Y$, Jin $M$, Zhang D. Circular RNA circPIP5K1A promotes non-small cell lung cancer proliferation and metastasis through miR-600/HIF-1alpha regulation. J Cell Biochem. 2019; 120(11):19019-30.

54. Zhou Y, Zheng X, Xu B, Chen L, Wang Q, Deng H, Jiang J. Circular RNA hsa_ circ_0004015 regulates the proliferation, invasion, and TKI drug resistance of non-small cell lung cancer by miR-1183/PDPK1 signaling pathway. Biochem Biophys Res Commun. 2019;508:527-35. 
55. Su H, Zou D, Sun Y, Dai Y. Hypoxia-associated circDENND2A promotes glioma aggressiveness by sponging miR-625-5p. Cell Mol Biol Lett. 2019;24:24.

56. Militello G, Weirick T, John D, Doring C, Dimmeler S, Uchida S. Screening and validation of IncRNAs and circRNAs as miRNA sponges. Brief Bioinform. 2017;18:780-8.

57. You X, Vlatkovic I, Babic A, Will T, Epstein I, Tushev G, Akbalik G, Wang M, Glock C, Quedenau C, et al. Neural circular RNAs are derived from synaptic genes and regulated by development and plasticity. Nat Neurosci. 2015;18:603-10.

58. Du WW, Yang W, Liu E, Yang Z, Dhaliwal P, Yang BB. Foxo3 circular RNA retards cell cycle progression via forming ternary complexes with p21 and CDK2. Nucleic Acids Res. 2016;44:2846-58.

59. Yang ZG, Awan FM, Du WW, Zeng Y, Lyu J, Wu D, Gupta S, Yang W, Yang BB. The circular RNA interacts with STAT3, increasing its nuclear translocation and wound repair by modulating Dnmt3a and miR-17 function. Mol Ther. 2017;25:2062-74.

60. Zeng Y, Du WW, Wu Y, Yang Z, Awan FM, Li X, Yang W, Zhang C, Yang Q, Yee A, et al. A circular RNA binds to and activates AKT phosphorylation and nuclear localization reducing apoptosis and enhancing cardiac repair. Theranostics. 2017;7:3842-55.

61. Yang Q, Du WW, Wu N, Yang W, Awan FM, Fang L, Ma J, Li X, Zeng Y, Yang $Z$, et al. A circular RNA promotes tumorigenesis by inducing c-myc nuclear translocation. Cell Death Differ. 2017;24:1609-20.

62. Zhang XL, Xu LL, Wang F. Hsa_circ_0020397 regulates colorectal cancer cell viability, apoptosis and invasion by promoting the expression of the miR138 targets TERT and PD-L1. Cell Biol Int. 2017;41:1056-64.

63. Lu D, Xu AD. Mini review: circular RNAs as potential clinical biomarkers for disorders in the central nervous system. Front Genet. 2016;7:53.

64. Legnini I, Di Timoteo G, Rossi F, Morlando M, Briganti F, Sthandier O, Fatica A, Santini T, Andronache A, Wade M, et al. Circ-ZNF609 is a circular RNA that can be translated and functions in myogenesis. Mol Cell. 2017;66:22-37.

65. Chen H, Liu Y, Li P, Zhu D. RE: novel role of FBXW7 circular RNA in repressing glioma tumorigenesis. J Natl Cancer Inst. 2019;111:435.

66. Hanahan D, Coussens LM. Accessories to the crime: functions of cells recruited to the tumor microenvironment. Cancer Cell. 2012;21:309-22.

67. Kugeratski FG, Atkinson SJ, Neilson LJ, Lilla S, Knight J, Serneels J, Juin A, Ismail S, Bryant DM, Markert EK, et al. Hypoxic cancer-associated fibroblasts increase NCBP2-AS2/HIAR to promote endothelial sprouting through enhanced VEGF signaling. Sci Signal. 2019;12:eaan8247.

68. Junttila MR, de Sauvage FJ. Influence of tumour micro-environment heterogeneity on therapeutic response. Nature. 2013:501:346-54.

69. Gacche RN, Meshram RJ. Targeting tumor micro-environment for design and development of novel anti-angiogenic agents arresting tumor growth. Prog Biophys Mol Biol. 2013;113:333-54.

70. Li D, Xie K, Zhang L, Yao X, Li H, Xu Q, Wang X, Jiang J, Fang J. Dual blockade of vascular endothelial growth factor (VEGF) and basic fibroblast growth factor (FGF-2) exhibits potent anti-angiogenic effects. Cancer Lett. 2016;377:164-73.

71. Rahbari NN, Kedrin D, Incio J, Liu H, Ho WW, Nia HT, Edrich CM, Jung K, Daubriac J, Chen I, et al. Anti-VEGF therapy induces ECM remodeling and mechanical barriers to therapy in colorectal cancer liver metastases. Sci Transl Med. 2016;8:135r-360r.

72. Barratt SL, Blythe T, Jarrett C, Ourradi K, Shelley-Fraser G, Day MJ, Qiu Y, Harper S, Maher TM, Oltean S, et al. Differential expression of VEGF-Axxx isoforms is critical for development of pulmonary fibrosis. Am J Respir Crit Care Med. 2017;196:479-93.

73. Huang $Y$, Hua $K$, Zhou X, Jin H, Chen X, Lu X, Yu Y, Zha X, Feng Y. Activation of the PI3K/AKT pathway mediates FSH-stimulated VEGF expression in ovarian serous cystadenocarcinoma. Cell Res. 2008;18:780-91.

74. Li CY, Ma L, Yu B. Circular RNA hsa_circ_0003575 regulates oxLDL induced vascular endothelial cells proliferation and angiogenesis. Biomed Pharmacother. 2017;95:1514-9.

75. Zou Y, Zheng S, Deng X, Yang A, Xie X, Tang H, Xie X. The role of circular RNA CDRlas/ciRS-7 in regulating tumor microenvironment: a pan-cancer analysis. Biomolecules. 2019;9:E429.

76. Sahni A, Khorana AA, Baggs RB, Peng H, Francis CW. FGF-2 binding to fibrin(ogen) is required for augmented angiogenesis. Blood. 2006;107:126-31.

77. Voisine P, Li J, Bianchi C, Khan TA, Ruel M, Xu SH, Feng J, Rosinberg A, Malik T, Nakai Y, Sellke FW. Effects of L-arginine on fibroblast growth factor 2induced angiogenesis in a model of endothelial dysfunction. Circulation. 2005;112:1202-7.
78. Yao HH, Zhao YJ, He YF, Huang DB, Wang W. Knockdown of AGGF1 inhibits the invasion and migration of gastric cancer via epithelial-mesenchymal transition through Wnt/beta-catenin pathway. Cancer Cell Int. 2019;19:41.

79. Watnick RS, Rodriguez RK, Wang S, Blois AL, Rangarajan A, Ince T, Weinberg RA. Thrombospondin-1 repression is mediated via distinct mechanisms in fibroblasts and epithelial cells. Oncogene. 2015;34:2823-35.

80. Zhuo W, Luo C, Wang X, Song X, Fu Y, Luo Y. Endostatin inhibits tumour lymphangiogenesis and lymphatic metastasis via cell surface nucleolin on lymphangiogenic endothelial cells. J Pathol. 2010;222:249-60.

81. He T, Qi F, Jia L, Wang S, Wang C, Song N, Fu Y, Li L, Luo Y. Tumor cellsecreted angiogenin induces angiogenic activity of endothelial cells by suppressing miR-542-3p. Cancer Lett. 2015;368:115-25.

82. He Q, Zhao L, Liu X, Zheng J, Liu Y, Liu L, Ma J, Cai H, Li Z, Xue Y. MOV10 binding circ-DICER1 regulates the angiogenesis of glioma via miR-103a-3p/miR-382-5p mediated ZIC4 expression change. J Exp Clin Cancer Res. 2019;38:9.

83. He Q, Zhao L, Liu Y, Liu X, Zheng J, Yu H, Cai H, Ma J, Liu L, Wang P, et al. Circ-SHKBP1 regulates the angiogenesis of $U 87$ glioma-exposed endothelial cells through miR-544a/FOXP1 and miR-379/FOXP2 pathways. Mol Ther Nucl Acids. 2018;10:331-48.

84. Hsiao KY, Lin YC, Gupta SK, Chang N, Yen L, Sun HS, Tsai SJ. Noncoding effects of circular RNA CCDC66 promote colon cancer growth and metastasis. Cancer Res. 2017;77:2339-50.

85. Li Y, Zheng F, Xiao X, Xie F, Tao D, Huang C, Liu D, Wang M, Wang L, Zeng F, Jiang G. CircHIPK3 sponges miR-558 to suppress heparanase expression in bladder cancer cells. EMBO Rep. 2017;18:1646-59.

86. Li J, Li Z, Jiang P, Peng M, Zhang X, Chen K, Liu H, Bi H, Liu X, Li X. Circular RNA IARS (circ-IARS) secreted by pancreatic cancer cells and located within exosomes regulates endothelial monolayer permeability to promote tumor metastasis. J Exp Clin Cancer Res. 2018;37:177.

87. Zboralski D, Hoehlig K, Eulberg D, Fromming A, Vater A. Increasing tumorinfiltrating T cells through inhibition of CXCL12 with NOX-A12 synergizes with PD-1 blockade. Cancer Immunol Res. 2017;5:950-6.

88. Tu C, Zeng Z, Qi P, Li X, Guo C, Xiong F, Xiang B, Zhou M, Liao Q, Yu J, et al. Identification of genomic alterations in nasopharyngeal carcinoma and nasopharyngeal carcinoma-derived Epstein-Barr virus by whole-genome sequencing. Carcinogenesis. 2018:39:1517-28.

89. Yi M, Cai J, Li J, Chen S, Zeng Z, Peng Q, Ban Y, Zhou Y, Li X, Xiong W, et al. Rediscovery of NF-kappaB signaling in nasopharyngeal carcinoma: How genetic defects of NF-kappaB pathway interplay with EBV in driving oncogenesis? J Cell Physiol. 2018;233:5537-49.

90. Wellenstein MD, de Visser KE. Cancer-cell-intrinsic mechanisms shaping the tumor immune landscape. Immunity. 2018;48:399-416.

91. Pullamsetti SS, Kojonazarov B, Storn S, Gall H, Salazar Y, Wolf J, Weigert A, ElNikhely N, Ghofrani HA, Krombach GA, et al. Lung cancer-associated pulmonary hypertension: role of microenvironmental inflammation based on tumor cell-immune cell cross-talk. Sci Transl Med. 2017;9:eaai9048.

92. Kulkarni A, Natarajan SK, Chandrasekar V, Pandey PR, Sengupta S. Combining immune checkpoint inhibitors and kinase-inhibiting supramolecular therapeutics for enhanced anticancer efficacy. ACS Nano, 2016;10:9227-42.

93. Ngambenjawong C, Gustafson HH, Pun SH. Progress in tumor-associated macrophage (TAM)-targeted therapeutics. Adv Drug Deliv Rev. 2017;114:206-21.

94. Li X, Liu CX, Xue W, Zhang Y, Jiang S, Yin QF, Wei J, Yao RW, Yang L, Chen LL. Coordinated circRNA biogenesis and function with NF90/NF110 in viral infection. Mol Cell. 2017:67:214-27.

95. Wang M, Yu F, Wu W, Zhang Y, Chang W, Ponnusamy M, Wang K, Li P. Circular RNAs: a novel type of non-coding RNA and their potential implications in antiviral immunity. Int J Biol Sci. 2017;13:1497-506.

96. Song M, Liu T, Shi C, Zhang X, Chen X. Bioconjugated manganese dioxide nanoparticles enhance chemotherapy response by priming tumorassociated macrophages toward M1-like phenotype and attenuating tumor hypoxia. ACS Nano. 2016;10:633-47.

97. Zhang $Y$, Zhang $Y, L i X$, Zhang M, LV K. Microarray analysis of circular RNA expression patterns in polarized macrophages. Int J Mol Med. 2017;39:373-9.

98. Stanton SE, Disis ML. Clinical significance of tumor-infiltrating lymphocytes in breast cancer. J Immunother Cancer. 2016:4:59.

99. Hu X, Li YQ, Li QG, Ma YL, Peng JJ, Cai SJ. ITGAE defines CD8+ tumorinfiltrating lymphocytes predicting a better prognostic survival in colorectal cancer. Ebiomedicine. 2018;35:178-88.

100. Wang WC, Zhang ZQ, Li PP, Ma JY, Chen L, Qian HH, Shi LH, Yin ZF, Sun B, Zhang XF. Anti-tumor activity and mechanism of oligoclonal hepatocellular 
carcinoma tumor-infiltrating lymphocytes in vivo and in vitro. Cancer Biol Ther. 2019;20:1187-94.

101. Weng Q, Chen M, Li M, Zheng YF, Shao G, Fan W, Xu XM, Ji J. Global microarray profiling identified hsa_circ_0064428 as a potential immuneassociated prognosis biomarker for hepatocellular carcinoma. J Med Genet. 2019:56:32-8.

102. Zhang Y, Velez-Delgado A, Mathew E, Li D, Mendez FM, Flannagan K, Rhim AD, Simeone DM, Beatty GL, Pasca DMM. Myeloid cells are required for PD1/PD-L1 checkpoint activation and the establishment of an immunosuppressive environment in pancreatic cancer. Gut. 2017:66:124-36.

103. Kim JM, Chen DS. Immune escape to PD-L1/PD-1 blockade: seven steps to success (or failure). Ann Oncol. 2016;27:1492-504.

104. Jiang X, Wang J, Deng X, Xiong F, Ge J, Xiang B, Wu X, Ma J, Zhou M, Li X, et al. Role of the tumor microenvironment in PD-L1/PD-1-mediated tumor immune escape. Mol Cancer. 2019;18:10.

105. Du WW, Fang L, Yang W, Wu N, Awan FM, Yang Z, Yang BB. Induction of tumor apoptosis through a circular RNA enhancing Foxo3 activity. Cell Death Differ. 2017;24:357-70.

106. Lasda E, Parker R. Circular RNAs co-precipitate with extracellular vesicles: a possible mechanism for circRNA clearance. PLoS One. 2016;11:e148407.

107. Li P, Liu C, Yu Z, Wu M. New insights into regulatory T cells: exosome- and non-coding RNA-mediated regulation of homeostasis and resident Treg cells. Front Immunol. 2016;7:574.

108. Kumar M, Sahu SK, Kumar R, Subuddhi A, Maji RK, Jana K, Gupta P, Raffetseder J, Lerm M, Ghosh Z, et al. MicroRNA let-7 modulates the immune response to Mycobacterium tuberculosis infection via control of A20, an inhibitor of the NFkappaB pathway. Cell Host Microbe. 2015;17:345-56.

109. Kohler UA, Bohm F, Rolfs F, Egger M, Hornemann T, Pasparakis M, Weber A, Werner S. NF-kappaB/RelA and Nrf2 cooperate to maintain hepatocyte integrity and to prevent development of hepatocellular adenoma. J Hepatol. 2016;64:94-102.

110. Lowe JM, Menendez D, Bushel PR, Shatz M, Kirk EL, Troester MA, Garantziotis S, Fessler MB, Resnick MA. p53 and NF-kappaB coregulate proinflammatory gene responses in human macrophages. Cancer Res. 2014; 74:2182-92.

111. Baratin M, Foray C, Demaria O, Habbeddine M, Pollet E, Maurizio J, Verthuy C, Davanture S, Azukizawa H, Flores-Langarica A, et al. Homeostatic NFkappaB signaling in steady-state migratory dendritic cells regulates immune homeostasis and tolerance. Immunity. 2015;42:627-39.

112. Syn NL, Wang L, Chow EK, Lim CT, Goh BC. Exosomes in cancer nanomedicine and immunotherapy: prospects and challenges. Trends Biotechnol. 2017;35:665-76.

113. Lu M, Huang B, Hanash SM, Onuchic JN, Ben-Jacob E. Modeling putative therapeutic implications of exosome exchange between tumor and immune cells. Proc Natl Acad Sci USA. 2014;111:E4165-74.

114. Dou Y, Cha DJ, Franklin JL, Higginbotham JN, Jeppesen DK, Weaver AM, Prasad N, Levy S, Coffey RJ, Patton JG, Zhang B. Circular RNAs are downregulated in KRAS mutant colon cancer cells and can be transferred to exosomes. Sci Rep. 2016;6:37982.

115. Steinbichler TB, Dudas J, Skvortsov S, Ganswindt U, Riechelmann H, Skvortsova II. Therapy resistance mediated by cancer stem cells. Semin Cancer Biol. 2018;53:156-67.

116. Brown HK, Tellez-Gabriel M, Heymann D. Cancer stem cells in osteosarcoma. Cancer Lett. 2017;386:189-95.

117. Sun J, Luo Q, Liu L, Song G. Low-level shear stress promotes migration of liver cancer stem cells via the FAK-ERK1/2 signalling pathway. Cancer Lett. 2018;427:1-8.

118. Wu Y, Zhang Y, Niu M, Shi Y, Liu H, Yang D, Li F, Lu Y, Bo Y, Zhang R, et al. Whole-transcriptome analysis of CD133+CD144+ cancer stem cells derived from human laryngeal squamous cell carcinoma cells. Cell Physiol Biochem. 2018:47:1696-710.

119. Talati PG, Gu L, Ellsworth EM, Girondo MA, Trerotola M, Hoang DT, Leiby B, Dagvadorj A, McCue PA, Lallas CD, et al. Jak2-Stat5a/b signaling induces epithelial-to-mesenchymal transition and stem-like cell properties in prostate cancer. Am J Pathol. 2015;185:2505-22.

120. Kashima H, Noma K, Ohara T, Kato T, Katsura Y, Komoto S, Sato H, Katsube $\mathrm{R}$, Ninomiya T, Tazawa H, et al. Cancer-associated fibroblasts (CAFs) promote the lymph node metastasis of esophageal squamous cell carcinoma. Int J Cancer. 2019;144:828-40.

121. Karagiannis GS, Poutahidis T, Erdman SE, Kirsch R, Riddell RH, Diamandis EP. Cancer-associated fibroblasts drive the progression of metastasis through both paracrine and mechanical pressure on cancer tissue. Mol Cancer Res. 2012;10:1403-18.

122. Avgustinova A, Iravani M, Robertson D, Fearns A, Gao Q, Klingbeil P, Hanby AM, Speirs V, Sahai E, Calvo F, Isacke CM. Tumour cell-derived Wnt7a recruits and activates fibroblasts to promote tumour aggressiveness. Nat Commun. 2016;7:10305.

123. Huang MS, Liu JY, Xia XB, Liu YZ, Li X, Yin JY, Peng JB, Wu L, Zhang W, Zhou HH, Liu ZQ. Hsa_circ_0001946 inhibits lung cancer progression and mediates cisplatin sensitivity in non-small cell lung cancer via the nucleotide excision repair signaling pathway. Front Oncol. 2019;9:508.

124. Zanotti S, Gibertini S, Blasevich F, Bragato C, Ruggieri A, Saredi S, Fabbri M, Bernasconi P, Maggi L, Mantegazza R, Mora M. Exosomes and exosomal miRNAs from muscle-derived fibroblasts promote skeletal muscle fibrosis. Matrix Biol. 2018;74:77-100.

125. Bhome R, Goh RW, Bullock MD, Pillar N, Thirdborough SM, Mellone M, Mirnezami R, Galea D, Veselkov K, Gu Q, et al. Exosomal microRNAs derived from colorectal cancer-associated fibroblasts: role in driving cancer progression. Aging (Albany NY). 2017;9:2666-94.

126. Yang F, Ning Z, Ma L, Liu W, Shao C, Shu Y, Shen H. Exosomal miRNAs and miRNA dysregulation in cancer-associated fibroblasts. Mol Cancer. 2017;16:148.

127. Schaefer L, Reinhardt DP. Special issue: extracellular matrix: therapeutic tools and targets in cancer treatment. Adv Drug Deliv Rev. 2016;97:1-3.

128. Lampi MC, Reinhart-King CA. Targeting extracellular matrix stiffness to attenuate disease: from molecular mechanisms to clinical trials. Sci Transl Med. 2018;10:eaao0475.

129. Vannitamby A, Seow HJ, Anderson G, Vlahos R, Thompson M, Steinfort D, Irving LB, Bozinovski S. Tumour-associated neutrophils and loss of epithelial PTEN can promote corticosteroid-insensitive MMP-9 expression in the chronically inflamed lung microenvironment. Thorax. 2017;72:1140-3.

130. Jurado AA, Rysa J, Szabo Z, Moilanen AM, Komati H, Nemer M, Ruskoaho H. Transcription factor PEX1 modulates extracellular matrix turnover through regulation of MMP-9 expression. Cell Tissue Res. 2017;367:369-85.

131. Borkham-Kamphorst E, Alexi P, Tihaa L, Haas U, Weiskirchen R. Plateletderived growth factor-D modulates extracellular matrix homeostasis and remodeling through TIMP-1 induction and attenuation of MMP-2 and MMP9 gelatinase activities. Biochem Biophys Res Commun. 2015;457:307-13.

132. Li P, Chen H, Chen S, Mo X, Li T, Xiao B, Yu R, Guo J. Circular RNA 0000096 affects cell growth and migration in gastric cancer. $\mathrm{Br} J$ Cancer. 2017;116: 626-33.

133. Luo YH, Zhu XZ, Huang KW, Zhang Q, Fan YX, Yan PW, Wen J. Emerging roles of circular RNA hsa_circ_0000064 in the proliferation and metastasis of lung cancer. Biomed Pharmacother. 2017;96:892-8.

134. Li X, He M, Guo J, Cao T. Upregulation of circular RNA circ-ERBB2 predicts unfavorable prognosis and facilitates the progression of gastric cancer via miR-503/CACUL1 and miR-637/MMP-19 signaling. Biochem Biophys Res Commun. 2019:511:926-30.

135. Fan Y, Xia X, Zhu Y, Diao W, Zhu X, Gao Z, Chen X. Circular RNA expression profile in laryngeal squamous cell carcinoma revealed by microarray. Cell Physiol Biochem. 2018;50:342-52.

136. Zhang J, Zhang Q, Lou Y, Fu Q, Chen Q, Wei T, Yang J, Tang J, Wang J, Chen Y, et al. Hypoxia-inducible factor-1alpha/interleukin-1beta signaling enhances hepatoma epithelial-mesenchymal transition through macrophages in a hypoxic-inflammatory microenvironment. Hepatology. 2018;67:1872-89.

137. Ackerman D, Simon MC. Hypoxia, lipids, and cancer: surviving the harsh tumor microenvironment. Trends Cell Biol. 2014:24:472-8.

138. Velasco-Hernandez T, Hyrenius-Wittsten A, Rehn M, Bryder D, Cammenga J. HIF-1alpha can act as a tumor suppressor gene in murine acute myeloid leukemia. Blood. 2014;124:3597-607.

139. Koh MY, Lemos RJ, Liu X, Powis G. The hypoxia-associated factor switches cells from HIF-1alpha- to HIF-2alpha-dependent signaling promoting stem cell characteristics, aggressive tumor growth and invasion. Cancer Res. 2011; 71:4015-27.

140. Ou ZL, Luo Z, Wei W, Liang S, Gao TL, Lu YB. Hypoxia-induced shedding of MICA and HIF1A-mediated immune escape of pancreatic cancer cells from NK cells: role of circ_0000977/miR-153 axis. RNA Biol. 2019;16(11):1592-603.

141. Chen H, Mao M, Jiang J, Zhu D, Li P. Circular RNA CDR1as acts as a sponge of miR-135b-5p to suppress ovarian cancer progression. Onco Targets Ther. 2019:12:3869-79.

142. Liang G, Liu Z, Tan L, Su AN, Jiang WG, Gong C. HIF1alpha-associated circDENND4C promotes proliferation of breast cancer cells in hypoxic environment. Anticancer Res. 2017;37:4337-43. 
143. Suzuki H, Zuo Y, Wang J, Zhang MQ, Malhotra A, Mayeda A. Characterization of RNase R-digested cellular RNA source that consists of lariat and circular RNAs from pre-mRNA splicing. Nucleic Acids Res. 2006;34:e63.

144. Vo JN, Cieslik M, Zhang Y, Shukla S, Xiao L, Zhang Y, Wu YM, Dhanasekaran SM, Engelke CG, Cao X, et al. The landscape of circular RNA in cancer. Cell. 2019;176:869-81.

145. Wang W, Wang J, Zhang X, Liu G. Serum circSETDB1 is a promising biomarker for predicting response to platinum-taxane-combined chemotherapy and relapse in high-grade serous ovarian cancer. Onco Targets Ther. 2019;12:7451-7.

146. Tian L, Cao J, Jiao H, Zhang J, Ren X, Liu X, Liu M, Sun Y. CircRASSF2 promotes laryngeal squamous cell carcinoma progression by regulating the miR-302b-3p/IGF-1R axis. Clin Sci (Lond). 2019;133:1053-66.

147. Wang G, Liu W, Zou Y, Wang G, Deng Y, Luo J, Zhang Y, Li H, Zhang Q, Yang $Y$, Chen $G$. Three isoforms of exosomal circPTGR1 promote hepatocellular carcinoma metastasis via the miR449a-MET pathway. Ebiomedicine. 2019:40:432-45.

148. Gao D, Qi X, Zhang X, Fang K, Guo Z, Li L. hsa_circRNA_0006528 as a competing endogenous RNA promotes human breast cancer progression by sponging miR-7-5p and activating the MAPK/ERK signaling pathway. Mol Carcinog. 2019;58:554-64.

149. Zhang X, Wang S, Wang H, Cao J, Huang X, Chen Z, Xu P, Sun G, Xu J, Lv J, Xu Z. Circular RNA circNRIP1 acts as a microRNA-149-5p sponge to promote gastric cancer progression via the AKT1/mTOR pathway. Mol Cancer. 2019;18:20.

150. Boutros M, Ahringer J. The art and design of genetic screens: RNA interference. Nat Rev Genet. 2008;9:554-66.

151. Abudayyeh OO, Gootenberg JS, Essletzbichler P, Han S, Joung J, Belanto JJ, Verdine V, Cox D, Kellner MJ, Regev A, et al. RNA targeting with CRISPRCas13. Nature. 2017:550:280-4.

152. Liang D, Wilusz JE. Short intronic repeat sequences facilitate circular RNA production. Genes Dev. 2014;28:2233-47.

153. Xiang JF, Yin QF, Chen T, Zhang Y, Zhang XO, Wu Z, Zhang S, Wang HB, Ge J, Lu X, et al. Human colorectal cancer-specific CCAT1-L IncRNA regulates longrange chromatin interactions at the MYC locus. Cell Res. 2014;24:513-31.

154. Wang L, Wang H, Song D, Xu M, Liebmen M. New strategies for targeting drug combinations to overcome mutation-driven drug resistance. Semin Cancer Biol. 2017:42:44-51.

155. Liu Y, Dong Y, Zhao L, Su L, Luo J. Circular RNAMTO1 suppresses breast cancer cell viability and reverses monastrol resistance through regulating the TRAF4/Eg5 axis. Int J Oncol. 2018:53:1752-62.

156. Zhu KP, Zhang CL, Ma XL, Hu JP, Cai T, Zhang L. Analyzing the interactions of mRNAs and ncRNAs to predict competing endogenous RNA networks in osteosarcoma chemo-resistance. Mol Ther. 2019:27:518-30.

157. Kun-Peng Z, Xiao-Long M, Chun-Lin Z. Overexpressed circPVT1, a potential new circular RNA biomarker, contributes to doxorubicin and cisplatin resistance of osteosarcoma cells by regulating ABCB1. Int J Biol Sci. 2018;14:321-30.

158. Xiong W, Ai YQ, Li YF, Ye Q, Chen ZT, Qin JY, Liu QY, Wang H, Ju YH, Li WH, Li YF. Microarray analysis of circular RNA expression profile associated with 5-fluorouracil-based chemoradiation resistance in colorectal cancer cells. Biomed Res Int. 2017;2017:8421614.

159. Shang J, Chen WM, Wang ZH, Wei TN, Chen ZZ, Wu WB. CircPAN3 mediates drug resistance in acute myeloid leukemia through the miR-153-5p/miR183-5p-XIAP axis. Exp Hematol. 2019:70:42-54.

160. Lee DH. Treatments for EGFR-mutant non-small cell lung cancer (NSCLC): The road to a success, paved with failures. Pharmacol Ther. 2017:174:1-21.

161. Lim SM, Syn NL, Cho BC, Soo RA. Acquired resistance to EGFR targeted therapy in non-small cell lung cancer: mechanisms and therapeutic strategies. Cancer Treat Rev. 2018;65:1-10.

162. Chen T, Luo J, Gu Y, Huang J, Luo Q, Yang Y. Comprehensive analysis of circular RNA profiling in AZD9291-resistant non-small cell lung cancer cell lines. Thorac Cancer. 2019;10:930-41.

163. Li S, Teng S, Xu J, Su G, Zhang Y, Zhao J, Zhang S, Wang H, Qin W, Lu ZJ, et al. Microarray is an efficient tool for circRNA profiling. Brief Bioinform. 2019:20(4):1420-33.

164. Wang K, Gan TY, Li N, Liu CY, Zhou LY, Gao JN, Chen C, Yan KW, Ponnusamy M, Zhang YH, Li PF. Circular RNA mediates cardiomyocyte death via miRNA-dependent upregulation of MTP18 expression. Cell Death Differ. 2017;24:1111-20.

165. Liu M, Wang Q, Shen J, Yang BB, Ding X. Circbank: a comprehensive database for circRNA with standard nomenclature. RNA Biol. 2019:16: 899-905.
166. Glazar P, Papavasileiou P. Rajewsky N: circBase: a database for circular RNAs. Rna. 2014;20:1666-70.

167. Ghosal S, Das S, Sen R, Basak P, Chakrabarti J. Circ2Traits: a comprehensive database for circular RNA potentially associated with disease and traits. Front Genet. 2013;4:283.

168. Chen X, Han P, Zhou T, Guo X, Song X, Li Y. circRNADb: a comprehensive database for human circular RNAs with protein-coding annotations. Sci Rep. 2016:6:34985.

169. Liu YC, Li JR, Sun CH, Andrews E, Chao RF, Lin FM, Weng SL, Hsu SD, Huang CC, Cheng C, et al. CircNet: a database of circular RNAs derived from transcriptome sequencing data. Nucleic Acids Res. 2016:44:D209-15.

170. Brucher BL, Jamall IS. Somatic mutation theory - why it's wrong for most cancers. Cell Physiol Biochem. 2016;38:1663-80.

171. Sonnenschein C, Soto AM. Carcinogenesis explained within the context of a theory of organisms. Prog Biophys Mol Biol. 2016:122:70-6.

172. Stone L. Prostate cancer: exosome RNA expression predicts high-grade disease. Nat Rev Urol. 2016:13:298-9.

\section{Publisher's Note}

Springer Nature remains neutral with regard to jurisdictional claims in published maps and institutional affiliations.

\section{Ready to submit your research? Choose BMC and benefit from:}

- fast, convenient online submission

- thorough peer review by experienced researchers in your field

- rapid publication on acceptance

- support for research data, including large and complex data types

- gold Open Access which fosters wider collaboration and increased citations

- maximum visibility for your research: over $100 \mathrm{M}$ website views per year

At $\mathrm{BMC}$, research is always in progress.

Learn more biomedcentral.com/submissions 